Poznańskie Studia Teologiczne 27(2013), s. 29-60.

Hans Waldenfels

Essen, Deutschland

\title{
Die Position der römisch-katholischen Kirche zum Dialog der Religionen
}

\section{Der Zeitrahmen}

\subsection{Die Zäsur in der Mitte des 20. Jahrhunderts}

1.1.1. „Drei Welten“: Der Beginn des Dialogs der Religionen gehört in die zweite Hälfte des 20. Jahrhunderts, das heißt in die Zeit nach dem 2. Weltkrieg. Weltgeschichtlich sind dafür zunächst eine Reihe nicht-religiöser Faktoren in Politik, Wirtschaft und Kultur verantwortlich. Das Ende des 2. Weltkriegs veränderte die politische Landkarte. Ohne dass es von vornherein so beabsichtigt war, kam es in der westlichen Welt zur Spaltung in einen demokratischen Block der westlichen Welt - die Erste Welt - und den so genannten Ostblock unter der ideologischen Führung der Sowjetunion - die Zweite Welt. 1949 wurden die zwei deutschen Staaten gegründet, 1961 die Berliner Mauer errichtet. Die Grenze zwischen den beiden ideologischen Blöcken verlief mehrere Jahrzehnte mitten durch Europa. Erst in der Nacht vom 9. zum 10. November 1989 fiel diese Mauer. Die Sowjetunion wurde schließlich 1991 aufgelöst.

1.1.2. Ende der Kolonialzeit: Mit dem Ende des 2. Weltkriegs setzte zugleich das Ende der Kolonialzeit ein. Die zahlreichen englischen und französischen Kolonien in Afrika wurden zu unabhängigen Staaten; es entstand die Dritte Welt. 1945 wurde in San Francisco die Organisation der Vereinten Nationen gegründet, in der gerade die Länder der 3. Welt ein eigenes Sprachrohr zur Friedenssicherung und $\mathrm{zu}$ ihrer wirtschaftlichen und kulturellen Entwicklung fanden. Hongkong, eine der letzten Bastionen des europäischen Kolonialismus, wurde 1997 an die Volksrepublik China zurückgegeben. Der Gesamtprozess endete im Zeichen des Endes der Eurozentrik ${ }^{1}$ und verbindet sich zugleich mit dem Ende des christlichen Abendlandes ${ }^{2}$.

\footnotetext{
${ }^{1}$ Vgl. Art. Eurozentrismus (H. Waldenfels): LThK 3, 1005.

${ }^{2}$ Vgl. R. Hummel, Religiöser Pluralismus oder Christliches Abendland? Herausforderung an Kirche und Gesellschaft, Darmstadt 1994.
} 
1.1.3 Lokalisierung: Die Unabhängigkeit der Völker Afrikas und Asiens brachte die Rückbesinnung auf deren kulturellen und religiösen Wurzeln mit sich. Sah es lange so aus, als ob die so genannten ,primitiven Religionen“, also die Stammesund Naturreligionen in den weithin schriftlosen Stämmen und Völkern endgültig zum Untergang verurteilt seien, so ist heute an vielen Stellen eine Neubelebung dieser Kulturelemente festzustellen. Religionen und Kulturen sind entsprechend als Grundlagen der jeweiligen Eigenständigkeiten zu betrachten. Diese überall festzustellende Tendenz zur Bewahrung und Wiederherstellung der lokalen Eigenheiten, ist jedoch nur eine Seite des heutigen Gesamtprozesses.

1.1.4. Globalisierung: Der Weltprozess steht zugleich unter dem Vorzeichen der Globalisierung. Diese hat es vor allem mit der weltweiten Auswirkung von zahlreichen technischen Neuerungen und Erfindungen zu tun. An erster Stelle sind hier die Entwicklungen im Bereich der modernen Kommunikationsmedien zu nennen und dabei der Einsatz des Fernsehens. Für die Bundesrepublik ist der 1, November 1954 insofern ein entscheidendes Datum, als seither das Erste Deutsche Fernsehen im Namen aller deutschen Hörfunksender landesweit tätig wurde und so ein Prozess einsetzte, der sich in den folgenden Jahren und Jahrzehnten zu einem weltweiten Netz verdichtete. Der Einfluss des heute globalen Kommunikationsnetzes, der seinen stärksten Ausdruck im Internet und in dem am 30. April 1993 weltweit zur allgemeinen Benutzung freigegebenen „World Wide Web" (= www) sowie im Mobilfunk gefunden hat, ist nicht zu überschätzen. In vielfacher Hinsicht trägt diese Entwicklung zum Zusammenbruch der Unterscheidung von Stadt- und Dorfkulturen bei, da heute kurzfristig die unterschiedlichsten Nachrichten aus aller Welt in deren fernste Winkel transportiert werden und so eine eigentümliche Einheit im Informationsbereich, verbunden mit einer stark uniformierten öffentlichen Meinung, erzeugt wird.

1.1.5. Mobilisierung: Dabei ist die weltweite Vernetzung der Kommunikation zwischen den Völkern, aber auch den Individuen nur eine Seite des heutigen Globalisierungsprozesses. Es kommen die Möglichkeiten heutiger Mobilisation auf unserer Erde bis zu den Aufbrüchen ins Weltall seit der ersten Landung auf dem Mond am 20. Juli 1969 hinzu. Die technischen Entwicklungen führten zugleich zu neuen, weltweit gültigen Normierungen, die ihrerseits die ideologischen Grenzen längst übersprungen und gesprengt haben. Das wiederum führt dahin, dass es jenseits aller Weltanschauungen und Ideologien zu neuen Uniformierungen und Vereinheitlichungen kommt, die interessanterweise nicht geistig, sondern materiell bedingt sind und im Bereich der Ökonomie einen eigenen Schwerpunkt erhalten.

1.1.6. Neuer Materialismus? Angesichts der fortschreitenden technischen Entwicklungen fühlen sich Menschen auf neue Weise in eine Herrschaftsposition 
auf dieser Erde versetzt. Die Wissenschaften greifen in Prozesse des Lebens ein, in deren Anfang und Ende. Menschliches Leben wird manipuliert und gesteuert. Man ringt um die Überwindung von Krankheiten, macht vor Eingriffen in die bislang als geistige Qualitäten angesprochenen Bereiche menschlichen Lebens nicht Halt. Geistige Funktionen werden nicht selten auf materielle Vorgänge im Gehirn reduziert. Was bleibt am Ende vom Verhältnis zwischen Geist und Materie? Was besagt noch menschliche Freiheit? Wie begründet sich menschliche Verantwortung?

1.1.7. Ethische Fragen: Die Frage nach dem Verhältnis von Gut und Böse stellt sich spätestens seit den neuen Erfahrungen menschlichen Scheiterns neu. Für den genannten Zeitraum seit der Mitte des 20. Jahrhunderts sind drei Ortsnamen zu Signalwörtern geworden: Auschwitz mit seinem Holocaust und dem nationalsozialistischen Willen zur Austilgung der Juden, Hiroshima mit dem Missbrauch der Atomkraft und Tschernobyl mit seiner ökologischen Signalwirkung. Inzwischen kommt der 11. September 2001 mit seinen zerstörerischen Anschlägen islamistischer Terroristen auf das World Trade Center in New York und auf das Pentagon in Arlington, Virginia, als neues Datum einer historischen Zäsur hinzu. Es bezieht auf neue Weise die Religionen in die zeitgeschichtliche Diskussion ein und eröffnet die Frage nach ihrer Ambivalenz. Spätestens seit dem 11. September kann die heutige Zeit mit Jürgen Habermas als ,postsäkularistisch“ angesprochen werden. Denn nicht das Ende der Religionen steht im Raum, sondern ein „revival of religions" bei aller Ambiguität, die damit verbunden ist. Seither wird entschieden gefragt, ob Religionen wirklich zum Frieden beitragen oder nicht selbst Ursache neuen Streits und neuer Konflikte sind.

1.1.8. Moralisches Bewusstsein: Dabei bedürfen die Menschen heute mehr als je zuvor eines neuen moralischen Bewusstseins. Denn die aufgezeigten Entwicklungen tragen auf unterschiedliche Weise dazu bei, dass es in der Welt nicht zu größerer Gleichheit kommt, sondern dass es immer mehr Gewinner und Verlierer gibt, dass die Schere zwischen Arm und Reich nicht enger, sondern weiter auseinander klafft. Die Unterschiede im Bereich der Bildung - in der Entwicklung von objektiven Bildungschancen, aber auch in den unübersehbaren Unterschieden bei den subjektiven Bildungsfähigkeiten - erscheinen unüberwindlich. Damit verbunden ist das Auftreten neuer sozialer Fragen, wobei das vielgesichtige Phänomen der Migration in aller Welt und die damit verbundene Vermischung von Menschen unterschiedlichster ethnischer und religiöser Herkunft nur einen Aspekt der Problematik darstellt ${ }^{3}$.

\footnotetext{
${ }^{3}$ Das FORUM MISSION (Luzern) thematisiert in seinen Jahrbüchern 4/2008 und 5/2009 die Frage unter dem Thema „Migration: Challenge to Religious Identity“.
} 
1.1.9. Multikulturalität und Pluralismus: An dieser Stelle sind einige weitere Stichwörter einzufügen: Wir sprechen heute von „Multikulturalität“ und können uns dem damit beschriebenen Faktum nicht entziehen, auch wenn die Frage des Umgangs mit diesem Phänomen unterschiedlich und mit verschiedenen Ergebnissen besprochen werden kann ${ }^{4}$. „Multikulturalität“ schließt die Erkenntnis ein, dass wir in einer unter vielfacher Hinsicht ,pluralistischen Gesellschaft“ leben. „Multikulturalität“ nennt selbst die Pluralität der Kulturen, impliziert aber auch das Faktum einer religiösen Pluralität bzw. eines religiösen Pluralismus. Die Analyse unserer Zeit führt somit, auch wenn der Blick zunächst auf die Vielzahl nicht-religiöser Faktoren fällt, notwendigerweise zur Religion bzw. zu den Religionen. Hier stellt sich dann die Frage, wie die einzelne Religion mit den gestellten Fragen und Problemen fertig wird und auf sie reagiert.

In diesem Beitrag geht es konkret um einen Teilaspekt der Frage. Wir fragen nach der Position des Christentums, genauer: nach der Position des römisch-katholischen Christentums.

\subsection{Das 2. Vatikanische Konzil}

1.2.1. Nach dem 21. Ökumenischen Konzil: Die heutige Position der römisch-katholischen Kirche kann nur beschrieben werden, wenn wir uns zunächst auf das am 25. Januar 1959 von Papst Johannes XXIII. angekündigte und vom 11. Oktober 1962 bis zum 8. Dezember 1965 durchgeführte Zweite Vatikanische Konzil beziehen. Zweifellos findet in der heutigen Einstellung der Kirche zur modernen Welt und darin auch zu den anderen Religionen nichts einen so nachhaltigen Widerhall wie dieses Konzil. Dabei waren in der Vorbereitung und zu Beginn des Konzils andere Religionen keineswegs ein beherrschendes Thema ${ }^{5}$.

Die Rede von einem „ökumenischen Konzil“ weckte Hoffnungen, die römischerseits nicht vom Begriff „Ökumenisches Konzil“ gedeckt waren. Denn „ökumenisch“ bedeutete in Verbindung mit Konzilien nichts anderes als „weltweit, universal“; anders gesagt: ein Konzil ist im römischen Verständnis eine Kirchenversammlung, in der die ganze katholische, den Papst anerkennende Kirche, geographisch, aber auch in ihren unterschiedlichen Riten, durch Repräsentanten

\footnotetext{
${ }^{4}$ Vgl. H. Waldenfels, Löscht den Geist nicht aus! Gegen die Geistvergessenheit in Kirche und Gesellschaft, Paderborn 2008, 69-83.

${ }^{5}$ Im deutschsprachigen Raum gibt es zwei grundlegende Kommentarwerke: die Anschlussbände K I-III zur 2. Auflage des LThK. Freiburg 1966-1968, sodann P. Hünermann, B. Hilberath (Hg.), Herders Theologischer Kommentar zum Zweiten Vatikanischen Konzil 1-5, Freiburg 2004-2006. Zu beachten ist, dass der erstgenannte Kommentar weitgehend von Teilnehmern und unmittelbaren Zeugen des Konzils verfasst wurde und daher in vielen Detailkenntnissen zuverlässiger ist als die weithin von Nachgeborenen verfassten Kommentare in der ca. 40 Jahre später erfolgten $\mathrm{Pu}$ blikation; deren Stärke liegt in der Beschreibung der Wirkungsgeschichte.
} 
vertreten ist. Die positive Erwartungshaltung gerade in der protestantischen Welt führte aber dahin, dass eine starke Gruppe nicht-katholischer christlicher „Beobachter" eingeladen wurde, deren Anwesenheit einen nicht zu überschätzenden Einfluss ausgeübt hat.

1.2.2. „Gaudium et spes“: Das Thema „,neue Welteinstellung“ hat seinen besonderen Ausdruck in einem Grundsatzdokument gefunden, der späteren Pastoralkonstitution 6 über die Kirche in der Welt von heute Gaudium et spes (GS). Dieses Dokument hatte lange Zeit keinen offiziellen Namen und wurde in der Diskussion als „Schema XIII“7 angesprochen. Zwar ist in ihm die Rede vom modernen Atheismus (vgl. Nr. 19-21), von der Aufgabe der Kirche in der heutigen Welt (Nr. 40-45), auch von der „Hilfe, die die Kirche von der heutigen Welt empfängt“" (Nr. 44), von der rechten Förderung der menschlichen Kultur, dem Kulturbegriff und der Pluralität der Kulturen (Nr. 53-62), doch wird weder ausführlich noch konkret von den Religionen gesprochen ${ }^{8}$. Dennoch formuliert gerade diese Konstitution prinzipiell, wie die Kirche und ihre Theologie in Zukunft mit der Welt umzugehen hat. In Nr. 4 heißt es:

„Zur Erfüllung (ihrer) Aufgabe obliegt der Kirche durch alle Zeit die Pflicht, die Zeichen der Zeit zu erforschen und im Licht des Evangeliums auszulegen, so dass sie in einer der jeweiligen Generation angemessenen Weise auf die beständigen Fragen der Menschen nach dem Sinn des gegenwärtigen und des zukünftigen Lebens und nach ihrem gegenwärtigen Verhältnis antworten kann. Es ist deshalb nötig, dass die Welt, in der wir leben, sowie ihre Erwartungen, Bestrebungen und ihr oft dramatischer Charakter erkannt und verstanden werden.“

Das elliptische Verhältnis von „Zeichen der Zeit“ und „Licht des Evangeliums" beschreibt in aller Klarheit, was die Kirche in der Welt von heute leisten kann und muss ${ }^{9}$. Dabei ist das Grundverhältnis zwischen den beiden Brennpunkten nicht zu vertauschen.

\footnotetext{
${ }^{6}$ Zur Problematik des neuen Begriffs „Pastoralkonstitution“ vgl. K. Rahner, Schriften zur Theologie, Einsiedeln 1967, 613-636.

${ }^{7}$ Vgl. dazu C. Moeller in seiner Einleitung zum Text in LThK ${ }^{2}$ K III 261; H.J. Sander glaubt es besser zu wissen und schreibt 2005 vom „Schema XVII“; vgl. P. Hünermann, B. Hilberath 4, 620-623.

${ }^{8}$ In Nr. 53 wird, wo von der Kultur und ihren Aufgaben die Rede ist, lediglich festgehalten, dass die Kulturen auch ,die Religion zu pflegen“ haben.

${ }^{9}$ Vgl. zu dieser Polarität ausführlicher H. Waldenfels, Kontextuelle Fundamentaltheologie, Paderborn ${ }^{4}$ 2005. P. Hünermann hat seinem fünfbändigen Werk einen weiteren Band folgen lassen mit dem Titel: Das Zweite Vatikanische Konzil und die Zeichen der Zeit, Freiburg 2006. In diesem Band skizziert eine große Gruppe von Mitarbeitern unterschiedlicher Provenienz recht eindringlich die Fülle heutiger Zeichen in Raum und Zeit.
} 
1.2.3. „Lumen gentium“: Wichtig ist ferner die an die erste Enzyklika Papst Paul VI.' Ecclesiam suam vom 6. August $1964^{10}$ erinnernde Nr. 16 der Dogmatischen Konstitution über die Kirche Lumen gentium (LG), in der alle Nichtgetauften auf die Kirche hingeordnet werden:

„Diejenigen, die das Evangelium noch nicht empfangen haben, werden auf das Volk Gottes auf verschiedene Weisen hingeordnet. In erster Linie freilich jenes Volk, dem der Bund und die Verheißungen gegeben worden sind und aus dem Christus dem Fleisch nach geboren ist (vgl. Röm 9,4f.), das seiner Erwählung nach um der Väter willen teuerste Volk: ohne Reue nämlich sind die Gaben und die Berufung Gottes (vgl. Röm 11,28f.). Die Heilsabsicht umfasst aber auch die, welche den Schöpfer anerkennen, unter ihnen besonders die Muslime, die, indem sie bekennen, dass sie den Glauben Abrahams festhalten, mit uns den einzigen Gott anbeten, den barmherzigen, der die Menschen am Jüngsten Tag richten wird. Aber auch anderen, die in Schatten und Bildern den unbekannten Gott suchen, auch solchen ist Gott selbst nicht fern, da er allen Leben und Atem und alles gibt (vgl. Apg 17,25-28). Die nämlich das Evangelium Christi und seine Kirche ohne Schuld nicht kennen, Gott jedoch mit aufrichtigem Herzen suchen und seinen durch den Spruch des Gewissens erkannten Willen unter dem Einfluss der Gnade in ihrem Wirken zu erfüllen versuchen, können das ewige Heil erlangen. Die göttliche Vorsehung verweigert auch denen die zum Heil notwendigen Hilfen nicht, die ohne Schuld noch nicht zur ausdrücklichen Anerkennung Gottes gelangt sind und nicht ohne göttliche Gnade ein rechtes Leben zu führen sich bemühen. Was immer sich nämlich an Gutem und Wahrem bei ihnen findet, wird von der Kirche als Vorbereitung für die Frohbotschaft und als von dem gegeben geschätzt, der jeden Menschen erleuchtet, damit er schließlich das Leben habe.“

Es gehört zu den grundlegenden Aussagen des Konzils, dass alle Menschen guten Willens in Beziehung stehen zu dem in Christus offenbar gewordenen neuen Menschen. So ist in GS Nr. 22 unter Hinweis auf die ausführlich zitierte Nr. 16 von LG die Rede von ,alle(n) Menschen guten Willens, in deren Herz die Gnade Gottes auf unsichtbare Weise wirkt".

1.2.4. „Nostra aetate“: Vor dem Hintergrund dieser beiden grundlegenden Konstitutionen sind die weiteren Konzilstexte zu lesen,, die von anderen Religionen handeln, vor allem das Dekret über die missionarische Tätigkeit der Kirche $A d$ gentes und die rangmäßig niedriger einzustufenden, aber in ihrer Wirkungsgeschichte herausragenden Deklarationen über die Haltung der Kirche zu den nichtchristlichen Religionen Nostra aetate (NA) und über die religiöse Freiheit Dignitatis humanae (DH).

\footnotetext{
${ }^{10}$ Schon in dieser Enzyklika thematisiert Papst Paul VI. insofern den interreligiösen Dialog, als er von einem „colloquium“, also einem ständigen „Dialog“ zwischen Gott und der Menschheit spricht, den die Kirche aufzugreifen hat und deren Adressaten in den in $L G$ genannten religiösen Kreisen angesprochen werden.
} 
Nostra aetate mit seiner Anknüpfung ,in unserer Zeit“"kann als Anbahnung einer neuen Einstellung zu den anderen Religionen verstanden werden ${ }^{11}$. Ausdrücklich genannt werden Hinduismus und Buddhismus, Islam und Judentum; China blieb schon aufgrund der politischen Situation unerwähnt. Doch sollte nicht vergessen werden, dass die Erklärung ursprünglich nicht die Pluralität der Religionen im Blick hatte, sondern auf das Judentum abzielte. Zwei starke Motive gab es für eine solche Erklärung: Einmal ließ die intensive exegetische Arbeit der Alttestamentler immer weniger Raum für eine antijüdische Polemik; sie musste für eine neue Grundeinstellung der Christen zum Judentum eintreten. Sodann blieb die Scham der deutschen Katholiken über die Untaten des Nationalsozialismus, über den Willen zur Ausrottung der jüdischen Rasse und den unsäglichen Prozess der Judenermordung in Auschwitz und an anderen Orten, an der nicht unwesentlich getaufte Katholiken als Täter und Henker beteiligt waren. Konkret führte am Ende die politische Lage im Nahen Osten dahin, dass die Judenerklärung in eine Erklärung zu den nichtchristlichen Religionen verlängert wurde. Es kam hinzu, dass auch die Bischöfe Asiens ihre Wünsche anmeldeten und die Beachtung ihrer Religionen einforderten.

1.2.5. „Dignitatis humanae“: Die Erklärung über die religiöse Freiheit DH knüpft bei der Würde des Menschen an und ist nicht zuletzt in Zeiten eines neuen Ringens um die Gewährung religiöser Freiheit für alle Menschen und alle religiösen Institutionen entstanden. In ihrer politischen Bedeutung kann sie nicht hoch genug eingeschätzt werden ${ }^{12}$. Schließlich leben wir in einer Zeit, in der gerade das Christentum in seinen verschiedenen Leitungsgremien nachdrücklich für die Freiheit religiöser Entscheidungen (auch der Entscheidung gegen eine religiöse Zugehörigkeit und so für den Freiraum eines gelebten Atheismus!) eintritt. Dafür fordert die Kirche heute aber auch eine entsprechende Freiheit für die Christen in Ländern wie der Türkei und den arabischen Emiraten, in der Volksrepublik China, in den afrikanischen Krisengebieten und neuerdings in Indien, Pakistan und Indonesien. Die Frage nach dem Umgang mit den Religionen ist längst kein ideologisches Glasperlenspiel mehr, sondern betrifft das alltägliche Leben und (mit dem Begriff Theodor Sundermeiers) die menschliche „Konvivenz“, das Zusammenleben der Menschen.

${ }^{11}$ Vgl. H. Waldenfels, Begegnung der Religionen, „Theologische Versuche“ I, Bonn 1990, 28-101. 40 Jahre nach NA wird die Erklärung erneut stark diskutiert; vgl. u.a. H. Waldenfels, Nostra aetate - vierzig Jahre danach, ZMR 89 (2005) 280-296; sodann J. Sinkovits, U. Winkler (Hg.), Weltkirche und Weltreligionen. Die Brisanz des Zweiten Vatikanischen Konzils 40 Jahre nach Nostra aetate, Innsbruck 2007.

12 Vgl. H. Waldenfels, Löscht nicht (A. 4) 111-139. 
1.2.6. Päpstliche Sekretariate bzw. Räte: Die Kirche des Konzils fand es nicht ausreichend, zu den verschiedenen Punkten Erklärungen abzugeben, sondern suchte nach Mitteln und Wegen, die für eine Nachdrücklichkeit und Vertiefung der angestoßenen Gedanken sorgen. Dazu gehörte schon zur Zeit des Konzils die Gründung von römischen Sekretariaten. Es begann 1960 mit der Gründung des Einheitssekretariats unter Leitung von Kardinal Augustin Bea; ihm folgten 1964 das Sekretariat für die Nichtchristen mit Kardinal Paulo Marella als erstem Präsidenten und 1965 das Sekretariat für die Nichtglaubenden unter dem Wiener Kardinal Franz König. Aus den drei Sekretariaten wurden später die Päpstlichen Räte für die Förderung der Einheit der Christen, für den Interreligiösen Dialog und für die Kultur. Die einzelnen Räte haben ihre je eigene Geschichte. Am geradlinigsten hat sich noch das Einheitssekretariat, der heutige Einheitsrat entwickelt. Der Rat für die Kultur wurde 1982 durch Paul VI. gegründet und 1993 von Johannes Paul II. mit dem Rat für den Dialog mit den Nichtglaubenden zusammengelegt. Das Sekretariat für die Nichtchristen wurde 1988 in Päpstlicher Rat für den Interreligiösen Dialog umbenannt. 2002 wurde Erzbischof Michael Fitzgerald als Nachfolger von Kardinal Francis Arinze zum Präsidenten des Rates bestellt. Als er 2006 abgelöst und zum Nuntius in Ägypten und Delegaten für die Liga arabischer Staaten ernannt wurde, wurde der Rat zeitweilig dem damaligen Leiter des Kulturrates Kardinal Paul Poupard unterstellt. Es herrschte zunächst eine gewisse Ratlosigkeit hinsichtlich seines weiteren Schicksals, doch nach der Regensburger Vorlesung Benedikts XVI. wurde 2007 die Selbständigkeit des Rates für den Interreligiösen Dialog wiederhergestellt und Kardinal Jean-Louis Tauran zum neuen Präsidenten ernannt. Wir erwähnen diese Unsicherheiten schon deshalb, weil sie zeigen, dass die Frage der konkreten Umsetzung des interreligiösen Dialogs keineswegs so eindeutig geklärt war, wie man es auf den ersten Blick vermuten sollte.

\section{Nach dem 2. Vatikanischen Konzil}

\subsection{Einleitung}

Vor dem Hintergrund der Skizze des weltgeschichtlichen Zeitrahmens und der mit den Weichenstellungen des 2. Vatikanischen Konzils gegebenen Ausrichtung der römischen Kirche lassen sich nun die anschließenden Entwicklungen in großen Zügen beschreiben. Diese Entwicklungen zeigen sich in einer Reihe von bemerkenswerten Facetten. Wir befassen uns vor allem mit den offiziell wirksamen und gelenkten kirchlichen Ereignissen und sehen von einer ausführlichen und detaillierten Beschäftigung mit den innertheologischen Auseinandersetzungen ab. Wir erinnern an wegweisende kirchliche Verlautbarungen, an denen die bleibenden Fragepunkte für den Bereich interreligiösen Dialogs hinreichend 
ablesbar sind. Dabei wird deutlich, was heute unter einem interreligiösen Dialog zu verstehen ist. Die Frage der Dialogfähigkeit und -bereitschaft ist in alle Richtungen zu stellen, an uns Christen genauso wie an viele andere. Es zeigt sich auch, dass der Dialog weniger eine Sache von Organisationen und Institutionen ist als von Menschen, die sich auf das Wagnis eines offenen Dialogs einlassen.

Inzwischen haben wir einen Punkt erreicht, an dem es nicht mehr um die Religionen im allgemeinen, sondern um die konkrete Begegnung mit den Vertretern und Angehörigen dieser und jener Religion geht. Der Dialog mit den Juden ist ein anderer als der mit Muslimen und Buddhisten. Doch die Welt hat Fragen an alle Religionen, die sie gemeinsam beantworten müssen. So ist auch die inhaltliche Seite des Dialog zu befragen. Geht es vor allem um Fragen, die zwischen den einzelnen Religionen im Raum stehen, oder geht es nicht vielmehr auch um Fragen, die die Menschen ganz allgemein, unabhängig von ihrer Zugehörigkeit zu einer bestimmten religiösen Tradition beschäftigen und beunruhigen? Die grundsätzlichen Lebensfragen und die Fragen des Überlebens, Fragen im Diesseits und Fragen nach dem Jenseits beunruhigen die Menschen heute wie zu allen Zeiten. In diesem Sinne liegt der Dialog wie ein weites offenes Feld vor uns.

\subsection{Kirchliche Verlautbarungen}

Wir beschränken uns hier auf solche kirchlichen Verlautbarungen, die bis heute nachwirken oder erneut zu Diskussionen in Welt und Kirche geführt haben oder führen ${ }^{13}$. Verschiedene Themen sind sehr bald angesprochen worden: das Verhältnis von Dialog und Mission, die Beziehung von Kultur und Evangelisation, der Widerstreit gegen die lateinamerikanischen Befreiungstheologien, der Einfluss des Marxismus auf die Theologie, der Zusammenhang von irdischem Glück und ewigem Heil, der universale Heilsanspruch des Christentums mit seiner Rückbindung an die Gestalt des Mensch gewordenen Jesus Christus, die Bedeutung der Pluralität der Religionen und ihre Bedeutung für das Heil der Menschen. $\mathrm{Zu}$ all diesen Themen hat es in den auf das Konzil folgenden Jahren wichtige römische Aussagen gegeben, die von der einen Seite dankbar aufgenommen, von anderen zornig zurückgewiesen worden sind.

${ }^{13}$ Nach Fertigstellung dieses Manuskripts ist eine von E. Fürlinger herausgegebene Ausgabe der einschlägigen Dokumente erschienen: Der Dialog muss weitergehjen. Ausgewählte vatikanische Dokumente zum interreligiösen Dialog, Freiburg 2009. Soweit die von uns zitierten Texte in diesem Band zu finden sind, verweisen wir auch auf diese Ausgabe mit der Abkürzung: Fürlinger + Seitenzahl. Die offiziellen Dokumente aus der Zeit von 1963 bis 1997 liegen in einer französischen Ausgabe vom Päpstlichen Rat für den Interreligiösen Dialog unter Federführung von F. Gioia vor; vgl. Le Dialogue Interreligieux dans l'Enseignement Officiel de l'Église Catholique (1963-1997), Éd. de Solemes 1998; es existieren auch eine frühere italienische und englische Ausgabe. 
2.2.1. „Evangelii nuntiandi“‘: Am 8. Dezember 1975, 10 Jahre nach Beendigung des Konzils, veröffentlichte Papst Paul VI. im Anschluss an die Bischofssynode des Jahres 1974 das Apostolische Schreiben Evangelii nuntiandi (EN) über die Evangelisierung in der Welt von heute ${ }^{14}$. Die Bischofssynode fand zeitlich parallel zur Schlussphase der Deutschen Synode statt, die von 1971 bis 1975 in Würzburg tagte und der Aufarbeitung der Konzilsimpulse dienen sollte ${ }^{15}$.

Dem Schreiben kommt in mehrfacher Hinsicht hohe Bedeutung zu: Einmal konkretisiert der Papst mit seiner Rede vom Auftrag der Evangelisierung die Gestalt des christlichen Missionsauftrags. Er tut das zu einer Zeit, in der der Begriff „Mission“ innerkirchlich vielerorts problematisch wurde und andere Religionen begannen, auch in den traditionell christlichen Ländern missionarisch tätig zu werden. Nachhaltig spricht er vom „Bruch zwischen Evangelium und Kultur“:

„Der Bruch zwischen Evangelium und Kultur ist ohne Zweifel das Drama unserer Zeitepoche, wie es auch das anderer Epochen gewesen ist. Man muss somit alle Anstrengungen machen, um die Kultur, genauer die Kulturen, auf mutige Weise zu evangelisieren. Sie müssen durch die Begegnung mit der Frohbotschaft von innen her erneuert werden. Diese Begegnung findet aber nicht statt, wenn die Frohbotschaft nicht verkündet wird.“ (Nr. 20)

In der inhaltlichen Bestimmung der Evangelisierung kommen dann alle jene Themen zur Sprache, die in der Folgezeit zum Teil kontrovers diskutiert werden: das universale Heil in Jesus Christus (Nr. 27), die Botschaft der Befreiung (Nr. 30.33), der Zusammenhang von Evangelisierung und „menschlicher Entfaltung“ bzw. Entwicklung (,promotio humana“), die Weisen der Bekehrung (Nr. 36f.), die Religionsfreiheit (Nr. 39). Wo vom Zeugnis die Rede ist, setzt Paul VI. das Zeugnis des Lebens an die erste Stelle (Nr. 41), erst dann folgen die verschiedenen Weisen worthafter Verkündigung. Unter den Adressaten der Evangelisierung nennt der Papst nach den Fernstehenden und Entchristlichten die nichtchristlichen Religionen (Nr. 53), am Ende alle Menschen. Träger der Evangelisierung ist die ganze Kirche, die als solche missionarisch ist (Nr. 59).

\footnotetext{
${ }^{14}$ Veröffentlicht vom Sekretariat der Deutschen Bischofskonferenz (DBK) in der Reihe: Verlautbarungen des Apostolischen Stuhls Nr. 2. Wir zitieren solche Dokumente nach der römischen Art mit Nennung der Nr. Die vor Beginn der Synode von der DBK eingereichte ausführliche Stellungnahme zum Planungspapier der Synode ist aufgrund der geforderten Geheimhaltung nicht öffentlich zugänglich gemacht worden.

${ }^{15} \mathrm{Vgl}$. Gemeinsame Synode der Bistümer der Bundesrepublik Deutschland. Offizielle Gesamtausgabe, I, Freiburg ${ }^{2}$ 1976. Das bis heute wirksamste Dokument ist der Bekenntnistext: Unsere Hoffnung. Ein Bekenntnis zum Glauben in dieser Zeit. Er endete in Teil IV mit einem starken Plädoyer für eine lebendige Einheit der Christen, für ein neues Verhältnis zur Glaubensgeschichte des jüdischen Volkes, für die Tischgemeinschaft mit den armen Kirchen und für eine lebenswürdige Zukunft der Menschheit. Von den anderen Religionen ist eher peripher die Rede im Beschluss: Missionarischer Dienst an der Welt; zur neuen Einstellung zu den Religionen vgl. L. Wiedenmann: ebd. 809.
} 
2.2.2. Zur Bedeutung der Theologie der Befreiung: Die Beschäftigung der Kirche mit den anderen Religionen blieb in der Folgezeit insofern zunächst noch verdeckt, als sich innerkirchlich die Aufmerksamkeit vor allem auf Lateinamerika richtete. Dort bahnte sich nach dem 2. Vatikanischen Konzil unter dem Namen „Theologie der Befreiung“ eine entschiedene Auseinandersetzung mit den sozialen und politischen Entwicklungen der armen Länder an, durch die sich die Kirche in ihrer Theologie und ihrer Pastoral herausgefordert sah ${ }^{16}$. Immerhin war Lateinamerika der zahlenmäßig größte katholische Kontinent. Unterschiedliche Strömungen wirkten hier zusammen. Politisch waren marxistisch-sozialistische Einflüsse nicht zu übersehen. Religiös gab es in nachkolonialistischer Zeit in der so genannten Volksfrömmigkeit ein neues Erwachen der in der Tiefe des Volkes nicht völlig untergegangenen, vor allem aus Afrika stammenden Kulte, die unterschiedliche Formen eines religiösen Synkretismus erzeugten. Außerdem wuchs der Einfluss nordamerikanischer Sekten und Freikirchen. Die lateinamerikanischen Ortskirchen reagierten auf verschiedenen Generalversammlungen des 1955 gegründeten und von Pius XII. approbierten Consejo Episcopal Latinoamercano (CELAM). Auf der von Paul VI. eröffneten Generalversammlung 1968 in Medellín / Kolumbien wurden drei Aufgaben herausgestellt: die Option für die Armen, für eine ganzheitliche Befreiung und die Entwicklung der Basisgemeinden. Das Pastoralprogramm zur Evangelisierung Lateinamerikas in Gegenwart und Zukunft wurde auf der von Johannes Paul II. eröffneten Generalversammlung in Puebla / Mexiko 1979 trotz erkennbarer Widerstände im Sinne Medellíns bestätigt. Demgegenüber fallen die beiden folgenden Generalversammlungen 1992 (in Erinnerung an die Entdeckung Amerikas vor 500 Jahren) in Santo Domingo / / Dominikanische Republik und 2007 in Aparecida / Brasilien in ihrer Ausstrahlung deutlich hinter Medellín und Puebla zurück. In der Zwischenzeit nahm Rom mit verschiedenen Dokumenten Stellung zur Befreiungstheologie. 1976 erschien ein Dokument der Internationalen Theologenkommission Zum Verhältnis zwischen menschlichem Wohl und christlichem Heil. Nach Puebla veröffentlichte schließlich die römische Glaubenskongregation unter Leitung von Kardinal Joseph Ratzinger zwei kritische Instruktionen, 1984 Libertatis nuntius, und 1986 Libertatis conscientia ${ }^{17}$.

Auch wenn wir auf die Kritik an der Befreiungstheologie hier nicht eingehen, ist doch festzuhalten, dass diese für unsere Fragestellung insofern relevant bleibt, als die Aufbrüche in Lateinamerika Anlass für ähnliche Bewegungen in

${ }^{16}$ Für einen guten Einblick vgl. Art. Befreiungstheologie (G. Collet, T. Hausmanninger, G. Gutiérrez, N. Mette): LThK ${ }^{3}$ 2, 130-137. Zum klassischen Einstieg wurde das 1971 erstmals erschienene Buch von G. Gutiérrez, Theologie der Befreiung, München - Mainz 1977. Vgl. auch I. Ellacuría, J. Sobrino (ed.), Mysterium Liberationis. Conceptos fundamentales de la Teología de la Liberación, I / II. Madrid 1990.

${ }^{17}$ Vgl. DBK-Reihe: Verlautbarungen des Apostolischen Stuhls Nr. 57 und 70. 
anderen Kontinenten waren. In Asien, vor allem in Indien, Sri Lanka, Korea und den Philippinen, dann auch in Afrika verbanden sich die sozial-politischen Impulse mit den aufkommenden Bemühungen im interreligiösen Bereich. So kam es 1970 im Anschluss an den Besuch Pauls VI. in Manila zur Gründung der Federation of Asian Bishops' Conferences (FABC), die die Bekämpfung der Armut, die Bemühungen um Inkulturation und den interreligiösen Dialog zu den zentralen Aufgaben der asiatischen Ortskirchen erklärte. Auch wenn die FABC strukturell lockerer als die CELAM organisiert erscheint, besticht sie durch eine sehr offene Dokumentation ihrer vielfältigen Konsultationen, deren Ertrag leider in der Gesamtkirche bislang zu wenig wahrgenommen und genutzt wird ${ }^{18}$.

2.2.3. Assisi 1986: Mit Johannes Paul II. gelangte zum letzten Mal ein bischöflicher Teilnehmer des 2. Vatikanischen Konzils in das oberste Leitungsamt der römischen Kirche, der zudem in hohem Maße sowohl an der Endredaktion von GS als auch an der Vorbereitung von DH beteiligt war. Im Rückblick auf sein Pontifikat fällt auf, wie oft der Gedanke des Erlösers im Titel einer Enzyklika erscheint ${ }^{19}$. J. Dupuis sieht den einzigartigen Beitrag Johannes Pauls II. zu einer entstehenden Theologie der Religionen aber vor allem darin, dass er - anders als Paul VI. - immer wieder vom aktuellen Wirken des Heiligen Geistes im religiösen Leben von Nichtchristen und in ihren religiösen Traditionen gesprochen hat ${ }^{20}$. So fragt er schon in seiner ersten Enzyklika RH Nr. 6:

"Geschieht es nicht manchmal, dass der feste Glaube von Angehörigen nichtchristlicher Religionen - ein Glaube, der auch eine Wirkung des Geistes der Wahrheit ist, der außerhalb der sichtbaren Grenzen des Mystischen Leibes wirkt - die Christen beschämt, wenn sie selbst sich dem Zweifel gegenüber den Wahrheiten öffnen, die Gott geoffenbart und durch die Kirche verkündigt hat?"“

In der Missionsenzyklika RM Nr.29, die am 7. Dezember 1990 erschien, schreibt er:

„So leitet uns der Geist, der , weht, wo er will' (Joh 3,8), der ,in der Welt wirkte, noch bevor Christus verherrlicht wurde', der, das Universum, alles umfassend, erfüllt und jede Stimme kennt' (Weish 1,7), dazu an, unseren Blick zu erweitern, um so sein zu jeder Zeit und an jedem Ort vorhandenes Wirken in Betracht zu ziehen. Es ist ein

${ }^{18}$ Die FABC-Dokumente sind bisher in vier Bänden unter dem Titel: For the Peoples of Asia: vol. 1 (1970-1991), ed. by G. Rosales, C.G. Arevalo; vol. 2 (1992-1997), ed. by F.-J. Eilers, Manila 1997; vol. 3 (1997-2001) und vol. 4 (2002-2006), ed. by F.-J. Eilers, Manila 2002 und 2007, erschienen. Vgl. zur Sache auch meine Anmerkungen zum Dokument "Ecclesiam in Asia" in H. Waldenfels, Auf den Spuren von Gottes Wort, „Theologische Versuche“ III, Bonn 2004, 559-577.

${ }^{19} \mathrm{Vgl}$. Redemptor hominis (1979 - RH), Redemptoris mater (1987); Redemptoris missio (1991 - RM).

${ }^{20}$ Vgl. J. Dupuis, Toward a Christian Theology of Religious Pluralism, Maryknoll, N.Y. 1997, 173-179. 
Aufruf, den ich selbst wiederholt gemacht habe und der mich bei den Begegnungen mit den verschiedenen Völkern geleitet hat. Das Verhältnis der Kirche zu anderen Religionen ist bestimmt von einem doppelten Respekt: ,dem Respekt vor dem Menschen bei seiner Suche nach Antworten auf die tiefsten Fragen des Lebens und vom Respekt vor dem Handeln des Geistes im Menschen' .“

Und er fährt fort:

„Die Begegnung zwischen den Religionen in Assisi wollte unmissverständlich meine Überzeugung bekräftigen, dass, jedes authentische Gebet vom Heiligen Geist geweckt ist, der auf geheimnisvolle Weise im Herzen jedes Menschen gegenwärtig ist'.“

Am 25. Januar 1986 hatte Johannes Paul II. erstmals von einem Gebetstreffen gesprochen, zu dem er Vertreter der verschiedensten Religionen einladen wollte, um mit ihnen um den Frieden in der Welt zu beten. Die Friedensenzyklika Pacem in terris vom 11. April 1963 war gleichsam das Vermächtnis, das Johannes XXIII. einer friedlosen und konfliktgeladenen Welt hinterlassen hatte. 1970 kam es in Kyoto nach vielen Konsultationen im Umkreis des Ökumenischen Weltrats der Kirchen zur Gründung der World Conference on Religion and Peace (WCRP), bei der auch Vertreter der katholischen Kirche mitwirkten. Vielerorts wurden Friedenskonferenzen veranstaltet. Auf dem 21. Evangelischen Kirchentag in Düsseldorf forderte Carl Friedrich von Weizsäcker 1985 ein Friedenskonzil der Kirchen. Statt eines solchen Konzils kam es am 27. Oktober 1986 zu einem Weltgebetstag. Die Einladung erging im Namen des Papstes durch den Päpstlichen Rat für Gerechtigkeit und Frieden Iustitia et Pax unter der Präsidentschaft Kardinal Roger Etchegarays an die christliche Ökumene und an Vertreter anderer Religionen. In der Reaktion auf diese Einladung gab es bis in kirchliche Kreise hinein auch spürbare Zurückhaltung; so gehörte Kardinal Ratzinger nicht zu den Teilnehmern in Assisi. Es wurde in Assisi ausdrücklich nicht gemeinsam gebetet. Vielmehr beteten die Vertreter der Religionen zunächst jeweils für sich. Am Ende versammelten sie sich in der Nähe der Grabeskirche des hl. Franz von Assisi, um wechselseitig Zeuge des Gebetes und der Erklärungen der anderen zu werden ${ }^{21}$.

Assisi wurde in der Folgezeit zu einem Anstoß und Vorbild für ähnliche Veranstaltungen in der ganzen Welt. Vor allem die 1968 in Rom gegründete, inzwischen ökumenisch zu nennende Communità die Sant'Egidio hat sich das Anliegen von Assisi zueigen gemacht und veranstaltet jedes Jahr in einem anderen Land ein interreligiöses internationales Friedenstreffen mit dem Ziel, sich besser kennen zu lernen und den Dialog der Religionen zu fördern. Es darf aber nicht unerwähnt bleiben, dass die Frage gemeinsamen Betens bis heute nicht eindeutig

${ }^{21}$ Die Friedensgebete von Assisi liegen in deutscher Sprache dokumentiert vor, mit einer Einleitung von Franz Kardinal König und einem Kommentar von H. Waldenfels (Freiburg 1987); vgl. auch E. Fürlinger 113-153. 
geklärt ist. Dass Juden und Christen miteinander beten können, ist kaum umstritten, zumal zahlreiche jüdische Gebete, die Psalmen und andere Hymnen, längst zum Gebetsschatz der Kirche gehören. Die Diskussion betrifft aber - zumal in unseren Breiten - nach wie vor das christlich-islamische Verhältnis und erst recht das Verhältnis zu den nicht-abrahamitischen Religionen ${ }^{22}$.

2.2.4. „Dialog und Verkündigung“: Am 19. Mai 1991 veröffentlichten der Päpstliche Rat für den Interreligiösen Dialog und die Kongregation für die Evangelisierung der Völker ein Dokument mit dem Titel Dialog und Verkündigung $(D V)^{23} .25$ Jahre nach NA war stellenweise der Eindruck entstanden, als ob die neue, vom Pluralismus bestimmte Weltsituation schon aus Gründen eines friedfertigen Umgangs der Menschen miteinander nach einer Ablösung der traditionellen Missionstätigkeit durch einen wie immer gearteten Dialog rufe. In dieser Situation erschien es angebracht, ein deutliches Wort über das Verhältnis von Dialog und missionarischer Verkündigung zu sagen. Ein ermutigender Impuls war der Weltgebetstag in Assisi. Der neue Text löste zugleich einen 1984 veröffentlichten Text Dialog und Mission (DM) ab. Er ist in seinen Begriffsbestimmungen, in der Beschreibung der Dialogebenen und der Motivierung des Dialogs sowie in der deutlichen christologischen Verankerung für die Folgezeit maßgeblich geblieben.

- Begriffe: Evangelisierung wird im Sinne von EN (vgl. 2.2.1) voll bestätigt und ist auch hier der neue Name für die christliche Mission.

Zum Dialog heißt es:

„Der Dialog kann auf verschiedene Weise verstanden werden. Zunächst meint er auf rein menschlicher Ebene reziproke Kommunikation, die zu einem gemeinsamen Ziel oder, noch tiefer verstanden, zu zwischenmenschlicher Gemeinschaft führt. Zum zweiten kann Dialog als eine Haltung des Respekts und der Freundschaft aufgefasst werden, eine Haltung also, die all jene Tätigkeiten durchdringt oder durchdringen sollte, welche den Evangelisierungsauftrag der Kirche wesentlich mittragen. Diese Haltung kann zu Recht als ,Geist des Dialogs' bezeichnet werden. Zum dritten meint Dialog und dies nun besonders im Kontext eines religiösen Pluralismus, alle, positiven und konstruktiven interreligiösen Beziehungen mit Personen und Gemeinschaf-

22 Die DBK hat am 24.6.2008 die früheren Leitlinien für multikulturelle Feiern von Christen, Juden und Muslimen (Arbeitshilfen Nr. 170)) durch eine überarbeitete Fassung: Leitlinien für das Gebet bei Treffen von Christen, Juden und Muslimen (ebenfalls Arbeitshilfen Nr. 170) ersetzt. Vgl. zur Sache auch H. Waldenfels, Christus und die Religionen, Regensburg 2002, 107-109; ders., Löscht nicht (A. 4) 157-169.

${ }^{23}$ Die deutsche Fassung ist veröffentlicht mit dem Untertitel: Überlegungen und Orientierungen zum Interreligiösen Dialog und zur Verkündigung des Evangeliums Jesu Christi, in der DBK-Reihe: Verlautbarungen des Apostolischen Stuhls Nr. 102; vgl. auch E. Fürlinger 470-509. 
ten anderen Glaubens, um sich gegenseitig zu verstehen und einander zu bereichern' (DM 3) und zwar im Gehorsam gegenüber der Wahrheit und im Respekt vor der Freiheit. Dies beinhaltet sowohl gegenseitige Zeugnisabgabe wie auch die Entdeckung der jeweils anderen religiösen Überzeugungen." (Nr. 9)

Außerdem werden die Begriffe Verkündigung als Weitergabe der Botschaft des Evangeliums und Bekehrung in seinen Tiefenschichten erklärt. Unter Religionen und religiösen Traditionen versteht DV zunächst die abrahamitischen Religionen, aber auch die religiösen Traditionen Asiens, Afrikas und andere Religionen; ausgeschlossen werden die „neuen religiösen Bewegungen“.

- Vier Arten des Dialogs: Die in DV Nr. 42 vorgenommene Aufzählung der vier Dialogarten haben sich inzwischen weitgehend durchgesetzt. Wie zuvor in DM wird unterschieden zwischen a) dem Dialog des Lebens, b) dem Dialog des Handelns, c) dem Dialog des theologischen Austausches und d) dem Dialog der religiösen Erfahrung. Der Weg führt also, auch wenn keine Rangordnung hergestellt werden soll, von der alltäglichen Nachbarschaftlichkeit (a) zum spirituellen Austausch religiöser Erfahrung (d). Dazwischen liegen die Bemühungen um gesellschaftliche Kooperationen im Bereich der Entwicklung und der Befreiung der Menschen (b) und der wissenschaftliche Diskurs, der zu vertieftem Verständnis und zu größerer Wertschätzung der Religionen führen soll (c).

Vielleicht sind die Ebenen a) und d) bislang zu wenig reflektiert worden, obwohl die häufigsten Begegnungen zwischen Angehörigen verschiedener Traditionen im Alltag und in der Nachbarschaft stattfinden und der geistliche Austausch den wahren Weg in das Innere anderer Religionen eröffnet. Sicherlich ist im Lebensalltag auch das anzusiedeln, was Felix Körner mit „Laiendiskussion“ bezeichnet ${ }^{24}$. Zur Ebene d) ist an dieser Stelle auf die Erfahrungen hinzuweisen, von denen religiöse Männer und Frauen, zumal Ordensleute in Indien zu berichten wissen und die andere im Umgang mit der Praxis des Zen gemacht haben ${ }^{25}$. Inzwischen haben die intermonastischen Begegnungen auch die westliche Welt erreicht. Monastische Klöster gehören heute zu den wichtigsten Stätten interreligiösen Austausches wie vor allem eines wahren Erfahrungsaustausches auf dem Weg eines (wenn zeitlich auch begrenzten) gemeinsamen Lebens ${ }^{26}$.

${ }^{24}$ F. Körner hat nicht zuletzt aufgrund seiner intensiven türkischen Erfahrungen zu Recht nachdrücklich auf die interreligiöse Debatte unter nicht formal-theologisch ausgebildeten Gläubigen, die „Laiendiskussion“ hingewiesen. Ich würde diese allerdings in den Dialog des Lebensalltags einordnen. Vgl. F. Körner, Kirche im Angesicht des Islam. Theologie des interreligiösen Zeugnisses, Stuttgart 2008, 23f.

${ }^{25}$ Vgl. dazu H. Waldenfels, Löscht nicht (A. 4) 148-156.

${ }^{26}$ Über Aktivitäten und Erfahrungen in diesem Bereich berichtet regelmäßig das von den Monastic Interreligious Dialogue Commissions herausgegebene, jährlich zweimal erscheinende International Bulletin (Editor: P. de Béthune, Monastère de Clerlande, B-1340 Ottingnies). 
$\mathrm{Zu} \mathrm{c)}$ wäre zu prüfen, ob und wieweit wissenschaftliche Beschäftigungen mit anderen Religionen als Teil des Dialogs angesehen werden können. Hier wäre sicher entschiedener auf den Unterschied zwischen der Theologie und den Religionswissenschaften zu achten. Unbestritten ist, dass Kooperationen im Bereich des Friedenseinsatzes, der Gerechtigkeit und der Entwicklungspolitik auf nationaler und internationaler Ebene auf ihre religiösen Motivationen hin überprüft werden können (und müssen).

- Voraussetzungen des Dialogs: Zu den Voraussetzungen des Dialogs gehört nach DV Nr. 15 eine grundsätzlich positive Sicht anderer religiöser Traditionen, wie sie im 2. Vatikanischen Konzil gefordert ist. Ausdrücklich genannt werden eine ausgewogene Haltung auf allen Seiten, Offenheit und Aufnahmebereitschaft, Selbstlosigkeit und Unparteilichkeit, Annahmebereitschaft von Unterschieden und möglichen Widersprüchen (Nr. 47). Die eigene Überzeugung ist keineswegs beiseite zu legen (Nr. 48).

Gerade weil in der Kirche immer wieder auf der unaufgebbaren Rolle Jesu Christi in der universalen Heilsgeschichte bestanden wird, sind aber auch folgende Sätze bedenkenswert:

„Während Christen weiterhin von ihrem Glauben, dass in Jesus Christus, dem einzigen Mittler zwischen Gott und dem Menschen (vgl. 1 Tim 2,4-6) die Offenbarung erfüllt ist, überzeugt bleiben, müssen sie sich auch daran erinnern, dass sich Gott in gewisser Weise auch den Anhängern anderer religiöser Traditionen gezeigt hat. Folglich haben sie sich den Überzeugungen und Werten anderer Menschen mit aufnahmebereitem Sinn zu nähern.“ (Nr. 48)

„Zudem gibt die in Jesus Christus geschenkte Fülle der Wahrheit nicht jedem einzelnen Christen die Garantie, dass er in deren Vollbesitz sei. Letztendlich wissen wir, dass die Wahrheit nicht einer Sache gleicht, die wir besitzen, sondern eine Person ist, der wir zugestehen müssen, von uns Besitz zu ergreifen. Dies ist ein nicht endender Prozess. Ohne ihre Identität zu verlieren, müssen Christen dazu bereit sein, von und durch andere Menschen die Werte ihrer Traditionen kennen zu lernen und zu empfangen. Der Dialog kann sie dazu bewegen, verwurzelte Vorurteile aufzugeben, vorgefasste Meinungen zu revidieren und manchmal sogar einer Reinigung ihres Glaubensverständnisses zuzustimmen.“ (Nr. 49)

Angesichts der immer wieder geäußerten Sorge, dass im Dialog die christliche Grundüberzeugung Schaden nehmen könnte, sind die hier gemachten Anmerkungen zur Wirksamkeit Gottes wie auch zur Wahrheitsbegegnung über die sichtbare Kirche hinaus bedenkenswert.

- Hindernisse des Dialogs: DV listet auch eine Reihe von Hindernissen und Schwierigkeiten des Dialogs auf: a) eine ungenügende Verwurzelung im eigenen Glauben, b) ungenügende Kenntnisse und mangelndes Verständnis für den Glau- 
ben und die Praxis anderer Religionen, c) kulturelle Differenzen wie unterschiedliche Bildungsstandards, sodann auch Sprachprobleme, d) sozio-politische und geschichtsbedingte Faktoren, e) Mängel in der Bestimmung der Grundbegriffe Bekehrung, Taufe, Dialog u.a., f) ,Selbstzufriedenheit und Mangel an Offenheit, was zu einer defensiven oder gar aggressiven Haltung führt“, g) fehlende Überzeugung vom Wert des interreligiösen Dialogs, h) Misstrauen gegenüber den Motiven des Dialogpartners, i) eine polemische Gesinnung, j) „Intoleranz, die oft durch die Vermischung mit politischen, wirtschaftlichen, rassischen und ethnischen Faktoren verschlimmert wird“, k) gewisse Züge des gegenwärtigen religiösen Klimas wie der wachsende Materialismus, religiöse Gleichgültigkeit u.a.m. (Nr. 52).

Wie schon angedeutet, sahen sich die beiden römischen Instanzen einerseits veranlasst, den interreligiösen Dialog grundsätzlich zu beschreiben, andererseits aber auch dafür zu sorgen, dass die christliche Verkündigung durch die Praxis des Dialogs nicht ihre Bedeutung verliert. Es wird daher im 2. Teil des Dokumentes sehr ausführlich der kirchliche Auftrag zur Verkündigung erläutert und dabei die Rolle der Kirche, der Inhalt der Verkündigung u.ä. besprochen. Im Ergebnis bleibt es aber dabei: Interreligiöser Dialog und Verkündigung sind aufeinander bezogen, aber nicht gegeneinander austauschbar (Nr. 77).

2.2.5. „Dominus Iesus“: Wenn nicht alles täuscht, ist bis in unsere Tage die Sorge um die Substanz des christlichen Glaubens größer als die Ausbildung der in DV angemahnten Grundhaltungen. Das beweist auf besondere Weise die am 6 . August 2000 von der Kongregation für die Glaubenslehre veröffentlichte und von Kardinal Ratzinger als Präfekt unterzeichnete Erklärung Dominus Iesus (DI) mit dem Untertitel „Über die Einzigkeit und die Heilsuniversalität Jesu Christi und der Kirche“27. Die Erklärung erinnert eingangs an den zuvor besprochenen Text DV, spricht aber dann von neuen Fragen, ,,auf die man einzugehen versucht, indem man neue Wege der Forschung einschlägt, Vorschläge entwickelt und Verfahrensweisen anregt, die eines sorgfältigen Unterscheidungsvermögens bedürfen“ (Nr. 3). Der Hintergrund dieser Feststellung wird aber nicht genauer erläutert.

- Hintergründe: An dieser Stelle ist zu erwähnen, dass katholische Theologen in der Zeit nach dem Konzil immer wieder von der römischen Glaubenskongregation überprüft und vielfach gemaßregelt wurden.

+ Der „Fall Küng“: Der prominente „Fall Küng“ liegt Jahre zurück. 1980 wurde ihm im Anschluss an die Veröffentlichung seines Buches Christ sein und

\footnotetext{
${ }^{27}$ Deutsche Übersetzung veröffentlicht als Nr. 149 der von der DBK herausgegebenen Reihe: Verlautbarungen des Apostolischen Stuhls; vgl. E. Fürlinger 510-549.
} 
seine dort vertretene Christologie die kirchliche Lehrerlaubnis entzogen ${ }^{28}$. Diese Verurteilung hatte zur Folge, dass Hans Küng sich auf vielfältige Weise in die Welt der Religionen einarbeiten und mit seinem Programm des Weltethos einen nachhaltigen Beitrag zur Entwicklung des interreligiösen Dialogs leisten konn$t^{29}$. Im Vergleich zu seinem Tübinger Lehrstuhl und Institut gab es nur wenige Orte der theologischen Ausbildung, die sich mit dem religiösen Pluralismus befassten. Der Bonner Lehrstuhl für Fundamentaltheologie war der erste an einer Katholisch-Theologischen Fakultät der Bundesrepublik, mit dem seit 1977 die Beschäftigung mit den Religionen als spezieller Auftrag verbunden ist. Anderswo waren es Orte der Lehrerausbildung, wo die Notwendigkeit verspürt wurde, sich dieser Thematik zuzuwenden.

+ Pluralistische Religionstheologie: Inzwischen übt auch im katholischen Raum die Pluralistische Religionstheologie (PRT) einen unübersehbaren Einfluss aus. Ursprünglich im angelsächsisch-protestantischen Raum beheimatet, wurde sie katholischerseits vor allem durch die Amerikaner Paul F. Knitter und Leonard Swidler, sodann durch Perry Schmidt-Leukel bekannt und vertreten ${ }^{30}$. In diesem Rahmen werden drei christliche Einstellungen zu anderen Religionen definiert: a) Exklusivismus: Allein das Christentum vermittelt universales Heil; noch strenger formuliert: nur wer Mitglied der Kirche (am Ende gar der römisch-katholischen Kirche) ist, wird gerettet (vgl. „Extra Ecclesiam nulla salus “ = „Außerhalb der Kirche kein Heil““31); b) Inklusivismus: Auch wenn in der Kirchenzugehörigkeit die Vollgestalt der Heilsvermittlung gesehen wird, können Menschen, die nicht durch die Taufe zur Kirche gehören, das Heil erlangen, wenn sie Gott „,mit

\footnotetext{
${ }^{28}$ München 1974. Vgl. zur theologischen Diskussion u.a. Diskussion über Hans Küngs „,Christ sein" mit Beiträgen von H.U. von Balthasar, A. Deissler u.a. Mainz 1976; L. Bertsch, M. Kehl (Hg.), Theologische Streitfragen im „Fall Küng“, Würzburg 1980. Der gesamte Hergang wird mit Verweis auf verschiedene Dokumentationen nachgezeichnet in H. Küng, Umstrittene Wahrheit. Erinnerungen, München 2007.

${ }^{29}$ Vgl. H. Küng, Projekt Weltethos, München 1990: ders., K.-J. Kuschel (Hg.), Erklärung zum Weltethos. Die Deklaration des Parlamentes der Weltreligionen, München 1993; ders. (Hg.), Ja zum Weltethos. Perspektiven für die Suche nach Orientierung, München 1995.

${ }^{30}$ Vgl. P.F. Knitter, No other Name? A Critical Survey of Christian Attitudes Toward the World Religions, Maryknoll, N.Y. 1985 (dt.: Ein Gott - Viele Religionen. Gegen den Absolutheitsanspruch des Christentums, München 1988); ders., Horizonte der Befreiung. Auf dem Weg zu einer pluralistischen Theologie der Religionen, Frankfurt - Paderborn 1997; L. Swidler (ed.), Toward a Universal Theology of Religion, Maryknoll, N.Y. 1987; ders., After the Absolute. The Dialogical Future of Religious Reflections, Minneapolis 1990; P. Schmidt-Leukel, Theologie der Religionen. Probleme, Optionen, Argumente, Neuried 1997; ders., Gott ohne Grenzen. Eine christliche und pluralistische Theologie der Religionen. Vgl. zur Sache H. Waldenfels, Fundamentaltheologie (A. 9) 426-434; H.-G. Schwandt (Hg.), Pluralistische Theologie der Religionen. Eine kritische Sichtung, Frankfurt 1998.

${ }^{31}$ Vgl. dazu ausführlicher mit weiteren Lit.-Angaben H. Waldenfels, Fundamentaltheologie (A. 9) 428f.; ders., Christus und die Religionen, Regensburg 2002, 58-61. $101 \mathrm{f}$.
} 
aufrichtigem Herzen suchen und seinen durch den Spruch des Gewissens erkannten Willen unter dem Einfluss der Gnade in ihrem Wirken zu erfüllen versuchen“ (LG Nr. 16); das aber kann dann ein Mensch auch als Angehöriger einer anderen Religion vollbringen (vgl. Karl Rahners Rede vom ,,anonymen Christen(tum) ${ }^{\text {‘32 }}$ ), c) Pluralismus: Nicht nur das Christentum, sondern auch andere Religionen sind ohne Christus- und Christentumsbezug heilsvermittelnde Wege. Bei diesen Erwägungen verschiebt sich zugleich die Frage nach dem „Ort“ der Heilsvermittlung. In theologischer Sprache vollzieht sich in der PRT eine Verschiebung von der Ekklesiozentrik über die Christozentrik zur Theozentrik und am Ende zur Soteriozentrik. Wo selbst Gott nicht mehr als Heil schenkender Mittelpunkt genannt wird wie in vielen asiatischen Religionen, bleibt die Frage nach Heil, Glück und Lebenserfüllung als solche immer noch bestehen. Anders gesagt, den Pluralisten bleibt in ihrem Religionsverständnis so oder so die Frage nach der Heils- bzw. Erlösungsorientierung (griech. sōtēría) bestimmend; das Heil als solches rückt somit ins Zentrum der Betrachtung. Jesu Bedeutung wird dabei völlig relativiert, im äußersten Fall gar marginalisiert; von der Christologie des Konzils von Chalkedon rückt die PRT in der Regel ausdrücklich ab.

+ Jacques Dupuis (1923-2004): Zur selben Zeit, in der die Glaubenskongregation DI veröffentlichte, unterzog sie das fundamentale Werk des belgischen Jesuiten Jacques Dupuis Toward a Christian Theology of Religious Pluralism (vgl. A. 20) einer Prüfung. Das Buch zeichnet zunächst in einem historischen Teil die theologische Entwicklung nach, die in unseren Tagen zur Auseinandersetzung mit dem religiösen Pluralismus geführt hat. Sodann listet es in einem systematischen Teil die Problemstellungen auf, die in heutiger Zeit im Hinblick auf das Verhältnis des Christentums zu anderen Religionen diskutiert werden. Nicht zuletzt sein langjähriger Aufenthalt in Indien qualifizierte den Dogmatikprofessor der Gregoriana für eine sachgerechte Vorstellung der vor allem aus Asien, aber auch aus anderen Kontinenten kommenden Rückfragen an die klassische Theologie. Rom beendete die Prüfung des Werkes mit einer am 24. Februar 2001 publizierten Notificatio $^{33}$. Diese enthielt zwar keine ausdrückliche Verurteilung des Buches, formulierte aber ihrerseits eine Reihe von kritischen Anmerkungen, wobei sie sich eingangs ausdrücklich auf die vorweg veröffentlichte Erklärung DI bezog. Der Notificatio geht es um folgende Themen: (1) die einzige und universale Heilsmittlerschaft Jesu Christi, (2) die Einzigartigkeit und Vollständigkeit der Offenbarung Jesu Christi, (3) das universale Heilswirken des Heiligen Geistes, (4) die

${ }^{32}$ Vgl. dazu H. Waldenfels, Fundamentaltheologie (A. 9) 430-432.

${ }^{33}$ Vgl. den Text in E. Fürlinger 550-557; dazu auch H. Waldenfels, Spuren (A. 18) 578-593; ders., Theologen unter römischen Verdacht: Anthony de Mello - Jacques Dupuis - Roger HaightJon Sobrino, StZ 226 (2008), 219-231. 
Hinordnung aller Menschen auf die Kirche, (5) den Wert und die Heilsfunktion der religiösen Traditionen.

- Zum Inhalt von DI ${ }^{34}$ : Der hier skizzierte theologische Hintergrund wird in DI nicht ausgeführt, darf aber nicht unberücksichtigt bleiben, wenn man dem Text gerecht werden will ${ }^{35}$. Man muss es dennoch auch heute noch unglücklich nennen, dass bei der Veröffentlichung des Dokumentes in Deutschland der erste Teil über die Bedeutung Jesu Christi zunächst völlig in den Hintergrund trat, weil die Aufmerksamkeit fast ganz der Nr. 17 und dem dort vertretenen Kirchenverständnis geschenkt wurde. In der Bemerkung über die kirchlichen Gemeinschaften, „,die den gültigen Episkopat und die ursprüngliche und vollständige Wirklichkeit des eucharistischen Mysteriums nicht bewahrt haben“ und daher „nicht Kirchen im eigentlichen Sinn" sind, erkannte sich die evangelische Kirche wieder. Entsprechend scharf waren die Reaktionen im Gesamtraum der Ökumene, aber auch von katholischer Seite ${ }^{36}$.

DI umfasste nach der Einleitung sechs Kapitel, von denen je die Hälfte sich mit Jesus Christus und der Kirche beschäftigen: I. Fülle und Endgültigkeit der Offenbarung Jesu Christi, II. Der Fleisch gewordene Logos und der Heilige Geist im Heilswerk, III. Einzigkeit und Universalität des Heilsmysteriums Jesu Christi, IV. Einzigkeit und Einheit der Kirche, V. Kirche: Reich Gottes und Reich Christi, VI. Die Kirche und die Religionen im Hinblick auf das Heil. Vergleicht man diese mit den zuvor aus der Notificatio über Dupuis genannten Themen, so zeigt sich, dass es sich prinzipiell um dieselben Fragestellungen handelt, Dupuis aber offensichtlich selbst für manche andere steht, die nicht genannt werden. In der vorliegenden Form kann man DI nicht dialogfördernd nennen.

- „Das Christentum und die Religionen“: Das gilt umso mehr, als die Internationale Theologenkommission mit Billigung ihres Vorsitzenden Kardinal Ratzinger schon am 30. September 1996 das Ergebnis einer mehrjährigen Diskussion mit dem Titel Das Christentum und die Religionen veröffentlicht hatte ${ }^{37}$. Merkwürdigerweise nimmt DI nirgendwo Bezug auf diese solide Arbeit. Dabei wollte dieses Dokument seinerseits ausdrücklich dem Dialog dienen. Denn:

„Die Bedeutung des Religiösen im Leben des Menschen und die zunehmenden Begegnungen unter den Menschen und den Kulturen machen einen interreligiösen Dia-

\footnotetext{
${ }^{34}$ Vgl. dazu H. Waldenfels, Spuren (A. 18) 409-428.

${ }^{35}$ Kardinal K. Lehmann hat in einer Presseerklärung vom 5.9.2000 versucht, den in DI gemeinten Problempunkten ein eigenes Profil zu geben; vgl. H. Waldenfels, Spuren (A.18) 411f.

${ }^{36}$ Vgl. M.J. Rainer (Hrsg.), «Dominus Iesus». Anstößige Wahrheit oder anstößige Kirche? Dokumente, Hintergründe, Standpunkte und Folgerungen, Münster 2001.

${ }^{37}$ Deutsche Übersetzung veröffentlicht in der DBK-Reihe: Arbeitshilfen Nr. 136. Dieser Text wird auch in E. Fürlinger nicht besprochen.
} 
log erforderlich, um die Probleme und Nöte der Menschen gemeinsam zu bewältigen, um den Sinn des Lebens zu erhellen und schließlich auch um gemeinsam für den Frieden und die Gerechtigkeit in der Welt einzutreten. Das Christentum bleibt faktisch nicht am Rande dieser Begegnung und des damit verbundenen Dialogs unter den Religionen, und es kann auch nicht am Rande bleiben. Wenn die Religionen manchmal Ursachen für Trennungen und Konflikte unter den Völkern gewesen sind und es auch noch immer sein können, so ist zu wünschen, dass sie heute vor unser aller Augen als Träger des Friedens und der Einheit erscheinen. Das Christentum hat dazu beizutragen, dass dies möglich wird.“ (Nr. 2)

Ein Beitrag zur Sache besteht dann in der Klärung der Frage, wie die katholische Kirche die Religionen in theologischer Hinsicht bewertet, zumal das Verhältnis der Christen zu den anderen Religionen, aber auch der Dialog von dieser Bewertung abhängt (Nr. 3). In der Beschreibung des status quaestionis einer Theologie der Religionen nennt das Dokument zunächst Gegenstand, Methode und Ziel. Zwei Linien werden für die Zeit vor dem 2. Vatikanischen Konzil genannt. Die eine verbindet sich mit den Namen Jean Daniélou und Henri de Lubac und setzt beim Noach-Bund an, einem kosmischen Bund, in dem sich Gottes Offenbarung in der Natur und im Gewissen der Menschen manifestiert, der in den Religionen fortlebt, ihnen positive Werte vermittelt, aber keine Heilsrelevanz besitzt; die zweite bei Karl Rahner, nach dem die Religionen ihre Anhänger auf dem Weg eines impliziten Glaubens zur Annahme der heilsnotwendigen Christusgnade verhelfen und in diesem Sinne durchaus Heilsrelevanz besitzen können. Die heutige Situation macht aber folgende Überlegungen erforderlich:

„Zuallererst wird das Christentum versuchen müssen, sich selbst im Kontext einer Pluralität der Religionen $\mathrm{zu}$ verstehen und $\mathrm{zu}$ bewerten; konkret wird es über die Wahrheit und die Universalität nachdenken müssen, die es beansprucht. An zweiter Stelle wird es den Sinn, die Funktion und den Eigenwert der Religionen in der Gesamtheit der Heilsgeschichte zu suchen haben. Die christliche Theologie wird schließlich die konkreten Religionen mit ihren genau definierten Inhalten zu studieren und zu prüfen haben, die dann mit den Inhalten des christlichen Glaubens konfrontiert werden müssen. Hierzu ist es notwendig, Kriterien aufzustellen, die eine kritische Diskussion dieses Materials und eine Hermeneutik ermöglichen, die dieses Material deuten." (Nr. 7)

In dieser Aufgabenstellung werden die beiden elliptischen Momente sichtbar, die wir zuvor im Blick auf GS Nr. 4 genannt haben: die Sachverhalte (,Zeichen der Zeit") und das Deutemoment (,Licht des Evangeliums“). Konkret heißt das im Blick auf die Religionen, dass man, um ein wirkliches Verständnis zu gewinnen, einen Standortwechsel vornehmen und versuchen muss, die Dinge nicht allein vom eigenen, sondern immer auch vom fremden Standpunkt aus zu betrachten. Dass angesichts dieser Forderung die eigene Position zwar nicht aufgegeben, wohl aber immer wieder überdacht und geklärt werden muss, ist dann 
eine Selbstverständlichkeit. Inhaltlich werden in dieser Eingangsüberlegung folgende Felder genannt: die Diskussion über die Heilsrelevanz der Religionen mit Blick auf die schon erwähnten Klärungsversuche: (exklusivistischer) Ekklesiozentrismus, Christozentrismus und Theozentrismus (Nr. 8-12), die Wahrheitsfrage, die Gottesfrage, die christologische Debatte, schließlich das Verhältnis von Mission und interreligiösem Dialog.

Im Folgenden sind nun nicht die einzelnen Argumentationsstränge im Detail vorzustellen. Es reicht zu erkennen, dass die Kommission bemüht war, die im Raum stehenden Fragen wahrzunehmen, zu diskutieren und dann in einigen grundlegenden Punkten zu hilfreichen Zwischenergebnissen zu gelangen. Das geschieht im 2. Teil des Dokumentes. Ausgehend von der Initiative des göttlichen Vaters im Erlösungswerk, behandelt es die einzigartige Mittlerschaft Jesu (unter Berücksichtigung der Wiederaufnahme patristischer Themen wie der Samenkörner des Wortes und der in GS Nr. 22 betonten Vereinigung des Sohnes Gottes mit jedem Menschen) und die Universalität des Heiligen Geistes, die ihren eigenen Ort im universalen Heilssakrament der Kirche ${ }^{38}$ finden. In diesem Zusammenhang kommt es zu einer Korrektur des viel zitierten Satzes „Extra Ecclesiam nulla salus " (Nr. 64-70), indem er im Anschluss an das 2. Vatikanische Konzil eingeschränkt wird auf diejenigen, ,die um die Heilsnotwendigkeit der Kirche wissen“ (Nr. 67). Im Ergebnis heißt es:

„So erhält der Satz ,Extra Ecclesiam nulla salus’ seinen ursprünglichen Sinn zurück, nämlich die Mitglieder der Kirche zur Treue zu ermahnen. Nachdem dieser Satz in das allgemeinere ,Extra Christum nulla salus' aufgenommen worden ist, steht er nicht mehr im Widerspruch zur Berufung aller Menschen zum Heil.“ (Nr. 70)

Aus diesen Vorgaben zieht das Dokument im 3. Teil Folgerungen für eine christliche Theologie der Religionen. Diese betreffen zunächst die Heilsrelevanz der Religionen. Hier gilt:

„Die Heilsmöglichkeit außerhalb der Kirche für diejenigen, die gemäß ihrem Gewissen leben, steht heute nicht mehr in Frage. Diese Rettung geschieht aber, wie im Vorausgegangenen gesehen, nicht unabhängig von Christus und seiner Kirche. Sie basiert auf der universalen Gegenwart des Heiligen Geistes, die vom österlichen Geheimnis Jesu nicht getrennt werden kann.“ (Nr. 81)

Es wird dann ausdrücklich Bezug genommen auf die Enzyklika Redemptoris missio von Johannes Paul II. und festgestellt, dass seine Beschreibung der Gegenwart des Heiligen Geistes eine Vertiefung der Konzilsaussagen darstellt; denn „die Gegenwart des Heiligen Geistes (wird) nicht nur in den einzelnen Menschen

${ }^{38}$ Vgl. GS Nr.1, wo von der Kirche gesagt wird, dass sie ,,in Christus gleichsam das Sakrament bzw. Zeichen und Werkzeug für die innigste Vereinigung mit Gott und für die Einheit des ganzen Menschengeschlechts ist“". 
guten Willens, sondern auch in der Gesellschaft und Geschichte, den Völkern, den Kulturen und den Religionen deutlicher herausgestellt" (Nr. 82):

„Es gibt ein universales Wirken des Heiligen Geistes, das von seinem besonderen Wirken im Leibe Christi, der die Kirche ist, nicht getrennt, aber auch nicht mit ihm verwechselt werden darf ( $R M$ 28f.)... Die Unterscheidung zwischen den beiden Wirkungsweisen des Heiligen Geistes darf nicht dazu führen, sie zu trennen, als ob nur die erste in Beziehung zum Heilsmysterium Christi stünde.“ (Nr. 82)

Daraus folgt:

„Nach dieser ausdrücklichen Anerkennung der Gegenwart des Geistes Christi in den Religionen kann die Möglichkeit nicht ausgeschlossen werden, dass sie als solche eine gewisse Heilsfunktion haben, das heißt, dass sie den Menschen helfen, ihr letztes Ziel zu erreichen, und zwar trotz ihrer Ambiguität. In den Religionen wird die Beziehung des Menschen zum Absoluten, seine transzendente Dimension thematisiert. Es wäre kaum denkbar, dass das vom Heiligen Geist in den Herzen der einzelnen Menschen Bewirkte eine Heilsrelevanz hätte, aber das vom selben Heiligen Geist in den Religionen und Kulturen bewirkte nicht. Die neueren Äußerungen des Lehramtes scheinen eine so krasse Unterscheidung nicht zu erlauben. Andererseits ist anzumerken, dass viele der genannten Texte nicht nur von den Religionen sprechen, sondern neben diesen auch die Kulturen nennen, die Geschichte der Völker usw. Auch sie alle können von Elementen der Gnade ,berührt' werden.“ (Nr. 84)

Es folgen Aussagen zur Offenbarung, zur Wahrheit als Problem zwischen der Theologie der Religionen und dem pluralistischen Ansatz und zum Verhältnis von interreligiösem Dialog und Heilsmysterium. Dem Pluralismus wird eine Veränderung des eigenen (christlichen) Glaubensverständnisses vorgehalten und das a) auf der historischen Ebene im Dreistufen-Schema (Exklusivismus, Inklusivismus, Pluralismus), b) auf der erkenntnistheoretischen Ebene in einer Relativierung der Wahrheitsfähigkeit theologischer Aussagen, c) auf der theologischen Ebene mit der Modifizierung und Reduzierung der eigenen Glaubensinhalte (Unbestimmtheit des Gottesbegriffs; Christologie) (Nr. 98-100). Demgegenüber wird an die in den „kontextuellen Theologien“ entwickelte Sensibilität gegenüber den Tiefenstrukturen der Herkunftskulturen mit zwei Hinweisen erinnert:

„1. Eine differenzierte Theologie der Religionen vor dem Hintergrund des eigenen Wahrheitsanspruchs ist die Basis für jeden seriösen Dialog und die notwendige Voraussetzung zum Verstehen der Vielheit der Ansätze und ihrer kulturellen Ausdrucksmittel. 2. Die literarische oder soziokulturelle Kontextualität stellt ein wichtiges Mittel für das Verstehen von Texten und Situationen dar, oft gar das einzige; sie ist ein möglicher Wahrheitsort, darf aber nicht mit der Wahrheit selbst identifiziert werden.." (Nr. 101)

Es gilt:

„Die Form des Dialogs darf den Inhalt des eigenen Glaubens und seiner Ethik nicht entkräften.“ (Ebd.) 
Was hier allgemein vorgetragen wird, ist an den Orten, an denen es zu einem unmittelbaren Kontakt mit bestimmten Religionen kommt, zu konkretisieren (Nr. 102). Gegen die Pluralisten besteht die Kommission auf einem vollen, unverkürzten Festhalten an den christologischen Dogmen. Abschließend wird darauf hingewiesen, dass der interreligiöse Dialog wesentlich durch zwei Grundfragen seinen wahren Sinn erhält: die Fragen nach der Bedeutung Gottes und nach der Bedeutung des Menschen. Es ist demnach in den verschiedenen Religionen sowohl nach dem Verständnis Gottes, der Gottheit oder des Absoluten und nach dem Verständnis des Menschen, seiner Personalität, seiner Gottebenbildlichkeit u.a.m. zu fragen.

Angesichts dieser Gedankengänge, die in einer der römischen Glaubenskongregation zugeordneten Kommission erörtert und formuliert worden sind, fragt man sich, warum die Glaubenskongregation ohne Bezug auf diese Ausarbeitung wenige Jahre später ein viel weniger durchdachtes und in seiner vorliegenden Form eher hinderliches Dokument publiziert hat. Ging es am Ende doch mehr um neue Verurteilungen als um die Eröffnung eines offenen und der Welt in ihren vielen Fragen und Nöten dienendes Verhalten?

\section{Begegnung der Religionen}

In einem letzten Schritt lenken wir den Blick auf zwei Punkte. Einmal hinterlässt die Beschäftigung der katholischen Kirche mit den Religionen in der nachkonziliaren Zeit trotz allem einen zwiespältigen Eindruck. Sodann ergibt sich aus den vorausgehenden Überlegungen, dass sich die Kirche nicht mit allgemeinen Feststellungen zum interreligiösen Dialog begnügen kann, weil jede Religion ihr eigenes Profil und ihre eigenen Orte hat, so dass sich die Kirche als Gesprächspartner auf jede Religion im einzelnen einstellen muss. NA bietet hier insofern einen ersten Hinweis, als die Konzilserklärung zumindest vier Religionen ausdrücklich anspricht.

\section{1. „Interreligiöser Dialog“}

Ähnlich wie in Deutschland mit Jürgen Habermas ${ }^{39}$ steht Benedikt XVI. in Italien im Gespräch mit dem Philosophen und früheren Senatspräsidenten Marcello Pera ${ }^{40}$. Obwohl Pera sich - auf Italienisch - als laico, das heißt, als Nichtglaubenden versteht, trifft er sich mit dem jetzigen Papst in der Skepsis gegenüber

\footnotetext{
${ }^{39}$ Vgl. J. Habermas, J. Ratzinger, Dialektik der Säkularisierung. Über Vernunft und Religion, Freiburg 2005.

${ }^{40}$ Vgl. Benedikt XVI., M. Pera, Ohne Wurzeln. Europa, Relativismus, Christentum, Islam, Augsburg 2005; zum italienischen Verständnis von .laico dort 104-113. 122-138.
} 
der Postmodernität und dem kulturellen Relativismus. Zu einem im Herbst 2008 erschienenen Buch Peras Perchè dobbiamo dirci cristiani ${ }^{41}$ hat der Papst einen einführenden Brief verfasst, in dem er u.a. schreibt:

\begin{abstract}
„Besonders bedeutungsvoll ist für mich Ihre Analyse der Begriffe eines interreligiösen und interkulturellen Dialogs. Sie erklären mit großer Klarheit, dass ein interreligiöser Dialog im strikten Sinne des Wortes nicht möglich ist, während umso mehr der interkulturelle Dialog drängt, der die kulturellen Konsequenzen der religiösen Grundentscheidung vertieft. Während über diese letzte ein wahrer Dialog nicht möglich ist, ohne dass der eigene Glaube eingeklammert wird, muss man sich in einer öffentlichen Auseinandersetzung den kulturellen Konsequenzen der religiösen Grundentscheidungen stellen. Hier sind der Dialog, eine gegenseitige Korrektur und eine wechselseitige Bereicherung möglich und notwendig."
\end{abstract}

Der Text ist ein deutlicher Ausdruck der Zurückhaltung, die wir beim jetzigen Papst schon seit seiner Zeit als Präfekt der Glaubenskongregation beobachten können ${ }^{42}$. Er ist auch nicht dadurch zu relativieren, dass Benedikt XVI. bei anderen Gelegenheiten den Begriff ,,interreligiöser Dialog“ ohne Schwierigkeiten verwendet. Zwar ist die Zurückhaltung insofern zu verstehen, als der Dialog zwischen den Religionen nicht deren Auflösung in eine Einheitsreligion oder einen religiösen Einheitsbrei zum Ziel haben, somit also nicht den jeweiligen Grundansatz und die daraus folgenden Grundentscheidungen zur Disposition stellen kann. Doch muss es im Dialog zwischen den Religionen, wenn auf einem gesunden Verhältnis von Glaube und Vernunft bestanden wird, möglich sein, mit allem nötigen Respekt alles zu fragen, was im Raum steht, also auch nach den Grundlagen des jeweiligen Glaubens im Sinne von 1Petr 3,15. Zu fragen und in Frage zu stellen und damit zu verneinen ist schließlich nicht dasselbe.

Im Übrigen ist es gefährlich, den Dialog zwischen den Religionen auf einen Dialog zwischen den Kulturen zu reduzieren. Schließlich sind die wahren Weltreligionen auch in einer nicht-religiösen Betrachtung nicht als reine Kulturfaktoren oder als Kulturprodukte anzusehen. Denn gerade als Weltreligionen beanspruchen Religionen, dass sie mit ihren jeweiligen Ansprüchen und Überzeugungen den Rahmen der einzelnen Kultur transzendieren. Schon deshalb müssen diese Religionen auch um wirksame Prozesse der Inkulturation bemüht sein, also um überzeugende und gültige Übersetzungen ihres jeweiligen Grundgehalts in die verschiedenen Kulturen der Welt. Die römische Kirchenleitung hat daher gut daran getan, den Päpstlichen Rat für den Interreligiösen Dialog nicht in den Kulturrat aufgehen zu lassen, sondern ihn als eigenständige Größe unter den Päpstli-

\footnotetext{
${ }^{41}$ Untertitel: Il liberalismo, L'Éuropa, l'etica, Milano 2008.

${ }^{42}$ Auch E. Fürlinger (348-352) spricht von einer „Akzentverschiebung in der Haltung zu den Religionen“.
} 
chen Räten wiederherzustellen. Dies aber war sicherlich die Folge einer konkreten Entwicklung, nämlich des Rufs nach einem effektiven Gespräch zwischen Christentum und Islam.

\subsection{Dialog der Religionen}

Inzwischen leben wir in einer Zeit, in der weniger vom Dialog der Religionen als vom Dialog mit bestimmten Religionen zu sprechen ist, wobei je nach Lage auch mehrere Religionen konkret miteinander ins Gespräch treten können, ja sollten. Ein solches mehrseitiges Gespräch ist zwischen den drei abrahamitischen Religionen Judentum, Christentum und Islam ein dringendes Gebot der Stunde. Umgekehrt können wir allerdings auch feststellen, dass keineswegs alle Religionen in gleicher Weise dialogfähig und dialogwillig sind, - eine Frage, die nicht nur nach Außen gestellt werden muss, sondern die jede Religion, das Christentum und seine Kirchen eingeschlossen, sinnvollerweise auch an sich selbst stellen muss ${ }^{43}$.

3.2.1. Christen und Juden: Im Dialog der Religionen nehmen die Juden schon deshalb einen besonderen Platz ein, weil das Judentum die Mutterreligion des Christentums ist. Nicht nur war Jesus von Nazareth ein Jude, - er hat auch seine jüdische Heilige Schrift in die Kirche mitgebracht, so dass sie bis heute integrierender Bestandteil der im Christentum verankerten Bibel ist. Für Kardinal König gibt es keinen Zweifel, dass es Johannes XXIII. war, der „ganz persönlich die ersten zarten Samen des christlich-jüdischen Dialogs säte“. Wir erinnern noch einmal daran, dass NA ursprünglich als Konzilserklärung über das Verhältnis der Kirche zu den Juden geplant war und aus verschiedenen, teilweise äußeren Gründen in einer Problemansage über das Verhältnis der Kirche zu den nicht-christlichen Religionen endete.

Die besondere Stellung der Juden hat bis heute zu anhaltenden Spannungen geführt. Gewiss haben sich seit der Konzilszeit alle Päpste um eine vertiefte Beziehung zu den Vertretern des jüdischen Volkes bemüht ${ }^{44}$. Zu diesen Bemühungen gehörten die Reisen in das Heilige Land, die wiederholten Besuche jüdischer Synagogen und schließlich auch der Gang Johannes Pauls II. und Benedikts XVI. nach Auschwitz. Die Besonderheit dieses Dialogs zeigt sich auch darin, dass er

${ }^{43}$ Im Vermächtnisbuch Franz Kardinals König, Offen für Gott - offen für die Welt. Kirche im Dialog, Hg. von C. Pongratz-Lippitt, Freiburg 2006, kommen die im folgenden anzusprechenden Dialogfelder zur Sprache; König beginnt dabei mit dem innerkirchlichen Dialog; vgl. zu den Juden 96-111, Zitat: 107. Vgl. auch H. Waldenfels, Löscht nicht (A.4) 35-39.

${ }^{44}$ Die wichtigsten Dokumente der Kirchen zum Judentum finden sich in den beiden Bänden: Die Kirchen und das Judentum. Bd. I. Dokumente von 1945 bis 1985, hg. von R. Rendtorff, H.H. Henrix. Paderborn - München 1988; Bd. II. Dokumente von 1986 bis 2000, hg. von H.H. Henrix, W. Kraus. Paderborn - Gütersloh 2001. 
schon vor Gründung des Sekretariats für die Nichtchristen im Einheitssekretariat, dem heutigen Rat für die Einheit angesiedelt war. Die sensible Rede von der Judenmission wurde tunlichst vermieden, zumal nach der Beseitigung des Attributs ,perfidi“ aus der traditionellen Karfreitagsfürbitte; diese Änderung wurde übrigens nicht erst im Konzil vorgenommen, sondern bereits 1948 durch Pius XII. veranlasst. Man muss es tragisch und unsensibel zugleich nennen, dass Benedikt XVI. als Folge seiner Wiederzulassung der tridentinischen Messform die Diskussion um die Formulierung der Karfreitagsfürbitte zugelassen und ihr nicht mit seiner Autorität und einem deutlichen Bekenntnis zur Formulierung der Bitte in der erneuerten Karfreitagsliturgie ein Ende gesetzt hat. Ereignisse dieser Art belasten nach wie vor das christlich-jüdische Verhältnis.

Von hoher Bedeutung sind aber für den historischen Bereich das wiederholt vorgetragene eindeutige Bekenntnis gegen jede Form von Antisemitismus und Antijudaismus. Dass hier die Haltung deutscher Katholiken und folglich auch des deutschen Papstes sehr genau beobachtet wird, konnte man an den Reaktionen auf die recht sorgfältig formulierte Rede Papst Benedikts XVI. bei seinem Auschwitz-Besuch am 28.5.2006 erkennen; manch einer vermisste dennoch die eindeutige Bitte um Vergebung der Schuld gegenüber den Betroffenen. Der hohe Grad von Verletztheit und Sensibilität bricht immer wieder auf und zeigt sich auch an der nicht enden wollenden, teilweise äußerst unsachlichen Polemik gegen Pius XII., die im Zusammenhang mit seiner geplanten Seligsprechung neu aufflammte.

Theologisch von größter Bedeutung ist die Überwindung der so genannten „Substitutionstheorie“, d.h. der Theorie, nach der der Sinai-Bund durch den Neuen Bund abgelöst erschien und die Erwählungsattribute des jüdischen Volkes auf die Kirche übertragen wurden. Inzwischen kann es als Gemeingut christlicher Theologie angesehen werden, dass Gottes Bund mit seinem Volk Israel ungekündigt fortbesteht. Es kommt hinzu, dass „die Juden“ nicht mehr als Forschungsobjekt einer Vergangenheitsgeschichte betrachtet werden können, sondern als unter uns lebende Zeitgenossen erkannt werden müssen und so Gesprächspartner und Subjekte wie wir selbst sind. Sie nehmen ihrerseits an unserem theologischen Diskurs teil ${ }^{45}$. Damit wird der jüdisch-christliche Dialog heute zu einem Modell für den Dialog überhaupt. Wenn irgendwo deutlich wird, dass „Interreligiösität“ nicht durch „Interkulturalität“ ersetzt werden kann, dann ist das hier der Fall.

3.2.2. Christlich-islamischer Dialog: Zwischen Christen und Muslimen ist der Dialog in den verschiedenen Teilen der Welt unterschiedlich entwickelt. Das hat mit der ungleichen gesellschaftlichen Stellung der Muslime in den einzelnen Ländern, aber auch mit ihrer unterschiedlichen ethnischen Herkunft zu tun. Die

\footnotetext{
${ }^{45}$ Vgl. H. Waldenfels, Fundamentaltheologie (A. 9) 419-423.
} 
Unterschiede fallen in der westlichen Welt auf, wenn man die USA mit Europa und dort nochmals Großbritannien, Frankreich und Deutschland vergleicht. Die Länder der Dritten Welt, zumal Afrikas, stellen ein eigenes Problem dar, auch die Länder mit einer überwiegend muslimischen Bevölkerung und umgekehrt die Länder mit einer stärker christlichen Tradition. Daher sollte man den Begriff „Dialog“ eher mit Zurückhaltung verwenden. Oft ist schon viel erreicht, wenn es zwischen muslimischen und christlichen Bevölkerungsteilen einigermaßen friedlich zugeht und der jeweils anderen Seite ein hinreichender Lebensraum und die Möglichkeit, sich religiös zu entfalten, eingeräumt wird. Dabei ist das Bewusstsein für die Religionsfreiheit in westlich-demokratischen Ländern deutlicher ausgeprägt, während um entsprechende Freiräume im Nahen und Mittleren Osten, in den arabischen Ländern und in der Türkei nach wie vor gerungen werden muss.

Einen entscheidenden Einschnitt in der heutigen Entwicklung des christlich-islamischen Verhältnisses stellte der 11. September 2001 dar, zumal die zerstörerischen Akte in den USA auf islamistische Terroristen zurückgingen und ein deutlicher Beweis dafür waren, dass die Religion nicht tot ist, sondern selbst Konfliktpotential in sich trägt. Längst ist Religion keine Privatsache mehr. Gerade im Blick auf den Islam ist das Verhältnis von Religion und Politik neu zu beden$\mathrm{ken}^{46}$.

Hohe Bedeutung für den christlich-islamischen Dialog hatte fünf Jahre nach dem 11.9.2001 die Regensburger Vorlesung Benedikts XVI. am 12. September $2006^{47}$. In der Einleitung dieser Vorlesung zitiert der Papst aus einem Gespräch, das Kaiser Manuel II. Palaeologos vermutlich 1391 mit einem gelehrten Perser geführt hat und in dem er sich - wie der Papst sagt - ,,in erstaunlich schroffer, für uns unannehmbar schroffer Form ganz einfach mit der zentralen Frage nach dem Verhältnis von Religion und Gewalt überhaupt an seinen Gesprächspartner“ wendet:

„Zeig mir doch, was Mohammed Neues gebracht hat, und da wirst du nur Schlechtes und Inhumanes finden wie dies, dass er vorgeschrieben hat, den Glauben, den er predigte, durch das Schwert zu verbreiten."

Das Zitat löste in der islamischen Welt helle Empörung aus ${ }^{48}$. Tatsächlich ist bis heute nicht geklärt, warum der Papst diesen Einstieg wählte, zumal das Zitat

${ }^{46}$ Vgl. H. Waldenfels, H. Oberreuter (Hg.), Der Islam - Religion und Politik, Paderborn 2004.

${ }^{47}$ Vgl. Text und erste Kommentare in Benedikt VI., Glaube und Vernunft. Die Regensburger Vorlesung, Freiburg 2006; das folgende Zitat: 15f. Die Diskussion um die Regensburger Rede ist nach wie vor nicht abgeschlossen: vgl. u.a. K. Wenzel (Hg.), Die Religionen und die Vernunft. Die Debatte um die Regensburger Vorlesung des Papstes, Freiburg 2007; C. Dohmen (Hg.), Die „Regensburger Vorlesung " Papst Benedikts XVI. im Dialog der Wissenschaften, Regensburg 2007.

${ }^{48} \mathrm{Vgl}$. H.O. Luthe, C.M. Wallbiner (Hg.), Anstoß und Aufbruch. Zur Rezeption der Regensburger Rede Papst Benedikts XVI. bei Christen und Muslimen, Bochum 2008. 
für den weiteren Verlauf der Rede entbehrlich war, zumal es in ihr in erster Linie nicht um das Verhältnis zu den Muslimen ging, sondern um das Verhältnis von Glaube und Vernunft ganz allgemein. Angesichts der immer neu aufbrechenden kriegerischen Auseinandersetzungen im Nahen und Mittleren Osten bekommt der nachfolgende Satz: „Nicht vernunftgemäß handeln ist dem Wesen Gottes zuwider" allerdings auch für den christlich-islamischen Dialog bleibende Aktualität. Das Thema "Glaube und Vernunft" muss Muslime aber schon deshalb provozieren, weil sie nach wie vor mit dem Vorwurf leben müssen, dass der Prozess der westlichen Aufklärung sie vielerorts bislang noch nicht erreicht hat.

Doch schon vor der Türkeireise des Papstes Ende November 2006 nahmen 38 islamische Gelehrte in einem Offenen Brief vom 13. Oktober 2006 zur Regensburger Rede Stellung und begrüßten trotz ihrer Kritik an einzelnen „Irrtümern“ und „Fehlern“ ausdrücklich seine Bemühungen ,gegen die Vorherrschaft von Positivismus und Materialismus im menschlichen Leben" sowie seinen Wunsch nach ,,aufrichtigem und offenem Dialog “49, In einer Rede an die Kurienkardinäle am 22. Dezember 2006 unterstrich Benedikt XVI. erneut die Bedeutung des Dialogs zwischen Christen und Muslimen und bemerkte:

„Wir Christen wissen uns solidarisch mit all denen, die gerade von ihrer religiösen Überzeugung als Muslime her gegen die Gewalt und für das Miteinander von Glaube und Vernunft, von Religion und Freiheit eintreten.“

Noch bedeutsamer als der Offene Brief der 38 war ein Jahr später der „Offene Brief und Aufruf von muslimischen Religiösen Führern“ an den Papst und die Führer der orthodoxen, orientalischen und protestantischen Kirchen, den das Royal Aal al-Bayt Institute for Islamic Thought in Amman veröffentlichte. Wegen der 138 ursprünglichen Unterzeichner des Briefes wird heute zumeist über den „Brief der 138“ gesprochen. Er ist auf weite Resonanz gestoßen. Interessanterweise knüpft er nicht an die Regensburger Vorlesung an. Vielmehr vertritt er unter Verweis auf Bibel und Koran, dass das Doppelgebot der Liebe Christen und Muslimen gemeinsam und Grund genug ist, zusammenzukommen im Sinne der Sure 3,64:

„Sag: Ihr Leute der Schrift! Kommt her zu einem Wort des Ausgleichs zwischen uns und euch! (Einigen wir uns darauf,) dass wir Gott allein dienen und ihm nichts (als Teilhaber an seiner Göttlichkeit) beigesellen. Und dass wir (Menschen) uns nicht untereinander an Gottes Statt zu Herren nehmen. Wenn sie sich aber abwenden, dann sagt: ,Bezeugt, dass wir (Gott) ergeben sind!'“ (Übersetzung R. Paret)

Ein Resultat des „Briefes der 138“ war im März 2008 die Gründung eines Katholisch-Islamisches Forums in Rom. Dieses Forum traf sich am 6. November

${ }^{49}$ Vgl. hierzu und zum Folgenden C. Troll, Christlich-muslimischer Dialog, StZ 226 (2008), $721 f$. 
2008 zu einem ersten Arbeitstreffen mit Benedikt XVI. im Vatikan. Thema dieses ersten Treffens, das vor allem einem gegenseitigen Kennenlernen diente, war das Gebot der Gottes- und Menschenliebe. Die vatikanische Einladung zum Dialog kann zugleich als späte Erfüllung einer Bitte angesehen werden, die schon vor Jahren Altkanzler Helmut Schmidt weitergegeben hat. In seinem Buch $\mathrm{Au}$ ßer Dienst berichtet er von einer Konferenz 1996 in Kairo unter der Ägide des ägyptischen Präsidenten Mubarak, in deren Verlauf der ägyptische Großscheich der Al Azhar-Universität Mohammed S. Tantawi ihn um die Vermittlung eines Treffens mit dem damaligen Papst gebeten hat:

„Immerhin hat Tantawi mich später gebeten, Johannes Paul II. eine Einladung zu einem Gespräch mit ihm nahezulegen; es reichte aber leider nicht einmal die Hilfe von Kardinal König, den Vatikan dazu zu überreden. So ist mir abermals die Notwendigkeit interreligiöser Toleranz demonstriert worden. ${ }^{\text {“50 }}$

$\mathrm{Zu}$ wünschen ist, dass das, was auf höchster Ebene in Gang kommt, seine Fortsetzung findet auf den niederen Ebenen des alltäglichen Lebens, wo Menschen sich nachbarschaftlich und familiär begegnen und in der jungen Generation neue Bindungen entstehen, die über die theoretischen theologischen Erörterungen hinaus nach praktischer religiöser Aufarbeitung rufen.

3.2.3. Interreligiöser Dialog in Asien: Zahlenmäßig sind Christentum und Islam heute die mitgliederstärksten Religionen der Welt. Entstehungsmäßig stehen sich Juden, Christen und Muslime auf eigentümliche Weise nahe. Nähe aber schafft immer neu Reibungen. So ist gerade das Verhältnis dieser Religionen zueinander seit langem konfliktgeladen. Wenn irgendwo der Aufruf zum Religionsfrieden gilt, dann hier.

Dennoch darf nicht übersehen werden, dass die asiatischen Religionen Indiens, Chinas und Japans in ihrer Andersartigkeit und Fremdheit weltweit eine ungeheure Faszination ausstrahlen. Dabei spielt besonders die Tatsache eine groBe Rolle, dass sie in ihren verschiedenen religiösen Praktiken deutlich andere Akzente setzen und vielfach zu einem Alternativprogramm zu den im Westen bekannten Religionen werden. Nicht Strukturen und Organisationen stehen hier im Vordergrund, sondern Übungen und das zumeist unter der Anleitung von erfahrenen Meistern. Deshalb bringt der Dialog etwa mit Hindus und Buddhisten auf einer rein theoretischen Ebene nicht viel ein. Das Feld der Übung und der daran anschließende Austausch über innere Erfahrungen stellt dafür eine viel stärkere Attraktion dar. Das wird auch deutlich, wo die zeitweilig im Westen boomenden neureligiösen Gemeinschaften in den Hintergrund treten und die klassischen Formen der Religionen Indiens, vor allem auch der Buddhismus in den

${ }^{50}$ Vgl. H. Schmidt, Außer Dienst. Eine Bilanz, München 2008, 62, auch 299-310. 
verschiedenen Gestalten Sri Lankas, Thailands, Vietnams, Tibets und Japans auszustrahlen beginnen.

Auch hier wird deutlich, dass ein interreligiöser Dialog sich nicht durch einen interkulturellen Dialog ersetzen lässt. Gerade im religiösen Erfahrungsaustausch können Christen noch viel lernen, zumal sich Christen über die dogmatischen und ethischen Normsysteme hinaus nach ihren je persönlichen religiösen Erfahrungen befragen lassen müssen. Hier reicht die Wiederholung satzhaften Wissens nicht aus, sondern die Rechenschaft des Glaubens beginnt mit der Zeugnisgabe über die religiösen Erfahrungen.

Was in monastischen Klöstern - wie angedeutet - längst begonnen hat, wird im Sinne einer Neubelebung religiös-christlichen Lebens auch in das konkrete Gemeindeleben Eingang finden müssen. Das kann zwar zunächst zu einer Neubelebung kleiner Gruppen bei gleichzeitigem weiteren Rückgang der Volkskirchen führen, dürfte aber doch ein Beitrag zur Zukunftsgestaltung der Kirchen sein. Beides aber gehört hier zusammen: das Wissen um den Grund christlichen Glaubens und die Befähigung, darüber Zeugnis zu geben, und die Erfahrung und der Umgang mit dem lebendigen Gott, in diesem Sinne Vernunft und Glaube; grundlegend aber sind die Glaubenserfahrungen ${ }^{51}$. Ihr folgt dann das, was im Englischen sharing heißt: anderen die Chance geben, an diesen Erfahrungen teilzuhaben.

\section{Stanowisko Kościoła Rzymskokatolickiego w kwestii dialogu międzyreligijnego}

\section{Streszczenie}

Po zarysowaniu wieloaspektowych zmian po II wojnie światowej (powstania nowych państw, migracji ludności, globalizacji i wpływu internetu, wielokulturowości i pluralizmu) autor artykułu przechodzi do poszukiwania odpowiedzi na pytanie, w jaki sposób religie odpowiadają na zachodzące zmiany, akcentując stanowisko Kościoła Rzymskokatolickiego. W związku z tym autor przedstawił nauczanie Soboru Watykańskiego II zawarte w dokumentach: Gaudium et spes, Lumen gentium, Nostra aetate, Dignitatis humanae. Następnie omówił późniejsze wypowiedzi Urzędu Nauczycielskiego Kościoła: list apostolski Evangelii nuntiandi Pawła VI czy dokument Papieskiej Rady ds. Dialogu Międzyreligijnego Dialog i przepowiadanie. Opierając się na wspomnianym dokumencie, dokonał analizy pojęcia dialogu, ukazując warunki jego prowadzenia, jak również przeszkody, które mogą go uniemożliwić. Została też podkreślona rola i wpływ Jana Pawła II na rozwój teologii religii oraz dialogu z religiami niechrześcijańskimi, odbywającego się podczas spotkań w Asyżu. Temat ten został dostrzeżony w deklaracji Dominus Jesus Kongregacji Nauki Wiary oraz w dokumencie Międzynarodowej Komisji Teologicznej Chrześcijaństwo a religie.

W ostatniej części artykułu omówiono dialog, jaki po Soborze Watykańskim II prowadzi Kościół Rzymskokatolicki z religiami niechrześcijańskimi, uwzględniając ich odrębność i specyfikę.

${ }^{51}$ Vgl. dazu ausführlicher H. Waldenfels, Löscht nicht (A. 4). 
Autor skupił się na aktywności papieża Benedykta XVI w dialogu z judaizmem, muzułmanami (z uwzględnieniem wykładu w Ratyzbonie i jego reperkusji w świecie muzułmańskim) oraz z religiami azjatyckimi.

\section{Słowa kluczowe}

religia, dialog, Kościół, nauczanie, Sobór Watykański II

\section{Keywords}

Religion, Dialog, Church, Teaching, Vatican II 